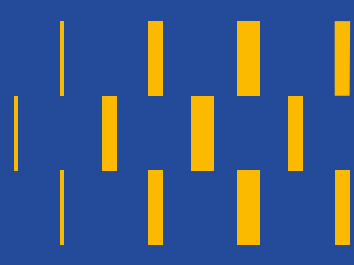

\title{
Tejer con la mente: el chumbe inga del Alto Putumayo colombiano como artefacto cultural y mental
}

\section{Weaving with the mind: the chumbe inga from the colombian Alto Putumayo as mental and cultural artifact}

\author{
Giovanna María Aldana Barahona ${ }^{1}$ (D) https://orcid.org/0000-0002-1436-8418 \\ Alfredo Sánchez Carballo² (D) https://orcid.org/0000-0002-3008-0318 \\ ${ }^{1}$ Instituto De Investigaciones Antropológicas, Universidad Nacional Autónoma de México, UNAM, \\ Ciudad de México, MÉXICO. Email: giomaralbar@gmail.com \\ ${ }^{2}$ Universidad Autónoma de Tamaulipas, Tamaulipas, MÉXICO. Email: alfredo.sanchez@uat.edu.mx
}

\section{Resumen}

Este artículo presenta los hallazgos de una investigación acerca de la faja llamada chumbe elaborada por las tejedoras ingas del pueblo Santiago-Manoy del Alto Putumayo en Colombia. El objetivo de este trabajo es dilucidar y comprender las características del chumbe inga como artefacto cultural y mental, en tanto condensa y es lugar de inscripción de las redes de significación de la cultura del pueblo inga. La metodología utilizada es de tipo cualitativa. En el trabajo de campo se aplicaron herramientas como la entrevista semiestructurada, la observación participante y un registro fotodocumental del chumbe y los pictogramas que contiene. Una de las principales conclusiones es que el chumbe inga, en tanto artefacto mental y cultural, es un "arte de la memoria" en el que el pueblo inga expresa su cosmovisión y su saber técnico y estético ancestral.

Palabras clave: chumbe, inga, Colombia, tejido, faja, pueblos indígenas.

\begin{abstract}
This article presents the findings of an investigation about the sash named chumbe, made by the inga weavers of the Santiago-Manoy town of the upper Putumayo in Colombia. The objective of this work is to elucidate and comprehend the characteristics of the inga chumbe as cultural and mental artifact, in so far as it condenses and it's a place of inscription of the significance nets of the inga people culture. The methodology used is qualitative. The tools applicated at the field work were semi-structured interview, the participant observation and a photographical register of the chumbe and the pictograms it contains. One of the main conclusions is that the Chumbe Inga, as a mental and cultural artifact, is an 'art of memory' in which the Inga people express their worldview and their ancestral technical and aesthetic knowledge.
\end{abstract}

Keywords: chumbe, inga, Colombia, weave, sash, indigenous peoples.

Recibido: 3 mayo 2019. Aceptado: 7 octubre 2019 


\section{Introducción}

Enseño a mi comunidad porque me parece importante esto, de que no se pierda nuestra cultura, nuestra tradición, que hay muchas personas que no pueden tejer estas prendas para ponerse la pacha [...]; nuestros diseños tienen historia; y me gustaría que ellos aprendan y con lo que yo sé, decirles que no se olviden, que no dejen pasar las culturas, que digan "oiga, ¿qué es esto?" que solamente quede en la historia, que no queden solamente en unas fotos y [...] que no se pierda nuestra costumbre, nuestra tradición (Ruby Rodríguez, tejedora inga, com. pers., mayo de 2018)

Este artículo tiene por objetivo discutir y comprender las características que hacen del chumbe inga un artefacto cultural y mental, en tanto condensa y es objeto de inscripción de las redes de significación de la cultura del pueblo inga. El presente trabajo es el resultado de las observaciones y análisis realizados en la población inga de Santiago-Manoy (en el departamento del Putumayo, en el sur de Colombia), cuyas mujeres elaboran y utilizan el chumbe como parte de su vestimenta. Para interpretar el chumbe inga como un artefacto cultural, nos basamos en la propuesta de Isava (2009) y Tavera y Johnston (2017); para la interpretación del chumbe como artefacto mental, utilizamos la propuesta teórica de Severi (2009). Los planteamientos de estos autores son adecuados y pertinentes ya que de este modo se logrará responder, al decir de Isava (2009), cuál es la virtualidad que hace cultural a un artefacto y, como plantea Severi (2009), cuáles son las operaciones constitutivas que lo hacen mental.

El chumbe es un tipo de faja que forma parte de la vestimenta tradicional de las mujeres del pueblo inga; se asemeja a otros tipos de fajas de diferentes pueblos indígenas ubicados en diferentes lugares del continente americano. En el valle de Sibundoy ubicado en la región del Alto Putumayo, en el sur del territorio que hoy se conoce como Colombia, el chumbe ocupa un lugar destacado como una prenda del vestuario femenino. Las mujeres lo portan principalmente para sostener la Pacha ${ }^{1}$ del "vestido tradicional" en las épocas de festividades, o por debajo de las prendas "modernas" de uso cotidiano.

El chumbe contiene varios pictogramas que las tejedoras llaman labores, ${ }^{2}$ las cuales representan parte de la cosmovisión del pueblo indígena. El chumbe y sus labores son la expresión de la identidad, la cultura y el sistema epistémico del mundo inga, y su contenido muestra la manera en que el pueblo inga comprende su propia existencia en relación con su entorno. Por otro lado, en su elaboración el chumbe mantiene las técnicas ancestrales heredadas del mundo andino, aunque se han agregado herramientas o materiales europeos para su elaboración, como el telar vertical o las lanas sintéticas, todo esto como resultado del proceso sincrético que vivieron los pueblos indígenas a lo largo del proceso colonial.

En consecuencia, el presente estudio es un análisis de las características de esta faja en su totalidad y, más específicamente, de los pictogramas (labores) que las mujeres ingas tejen en ella. Nos basaremos en la perspectiva de la antropología de la memoria (Severi, 2009) y de la sociología cultural (Isava, 2009; Tavera y Johnston, 2017). Con el fin de realizar una recopilación visual

$1 \quad$ Falda del vestido tradicional inga.

2 Las ingas llaman labores a cada una de las figuras simbólicas que se tejen en el chumbe; esta explicación se desarrollará con mayor amplitud más adelante. 
a los pictogramas, también nos basamos en la sociología visual siguiendo la idea de Williams (2016), quien indica que "[l]a sociología visual puede definirse como un conjunto de herramientas de técnicas basadas en imágenes que se utilizan para recopilar, analizar y presentar datos. Quizás el componente más obvio de la sociología visual es su énfasis en las imágenes" (pp. 102-103).

De esta manera pretendemos aportar en la actualización y análisis con metodologías que faciliten la captación del pensamiento y el saber indígena con la misma relevancia que se le ha otorgado al pensamiento occidentalizado. Lo anterior es una forma de resarcir el olvido, el relegamiento y el desdén con que se ha tratado el saber indígena en tiempos coloniales y republicanos, posición que prevalece en la actualidad.

En este sentido, aquí sostenemos que el chumbe es más que una prenda de vestir: es una forma sofisticada de significación que da cuenta del vasto conocimiento del pueblo inga, lo cual le da características de artefacto cultural y mental distinguible dentro de la variedad de otros objetos y artefactos usados por este pueblo. En el chumbe, los ingas plasman y transmiten una manera particular y compleja de interpretar su relación con la naturaleza y los acontecimientos de su propia existencia en el mundo, su estética, así como su conocimiento intelectual y emocional, es decir, su cosmovisión. Esta afirmación servirá como guía para la distribución discursiva de todo el texto.

La estructura del documento está organizada de la siguiente manera: en la primera sección presentamos un breve contexto sociohistórico de la región del valle de Sibundoy, donde está localizado el municipio de Santiago-Manoy, lugar en que se realizó el trabajo de campo. En segundo lugar, se encuentra el marco teórico a partir del cual discutimos dos categorías de análisis fundamentales: artefacto cultural y mental. En una tercera parte exponemos la estrategia metodológica que se aplicó para este análisis de la información recabada. En una cuarta parte se describen los hallazgos. Finalmente, se presentan las conclusiones del estudio.

\section{Contexto sociohistórico}

\section{El pueblo inga y su ubicación en el territorio colombiano}

Los registros antropológicos sobre el establecimiento de los ingas -en lo que hoy es territorio colombiano- indican que este grupo llegó a la región como parte de un mitimae $e^{3}$ del Tawantinsuyu por decreto del Shapa Inka Waina Qhapaq en 1492, ${ }^{4}$ para la expansión y protección de la frontera norte que formaba parte del Chinchaysuyus (Ramírez de Jara y Urrea, 1990; Ministerio de Cultura Colombia, 2016). Este pueblo se ubica en diferentes puntos de Colombia, pero la población mayor se encuentra en la región denominada valle de Sibundoy, la cual está conformada por los municipios de Santiago, San Francisco, San Andrés, Colón y

3 Los mitimaes o mitmaquna fueron una forma de organización política dentro del Tawantinsuyu. Consistían en grupos de familias a los que se enviaba a las fronteras para ampliarlas y protegerlas. Estos grupos no eran de pequeño tamaño; se trataba de familias enteras con diferentes cargos, entre las que se encontraban también los guerreros y los dirigentes intermedios del grupo. Siempre mantenían sus vínculos de reciprocidad y de parentesco con sus centros nativos (Rostworowski, 1999).

4 Nombre qhichwa del llamado por los europeos Imperio inca.

5 Chinchay en español se traduce como 'ocelote' y también indica el punto cardinal norte. Suyu se traduce como lugar. 
Sibundoy, pertenecientes al departamento del Putumayo. Esta región ha pasado, al igual que sus habitantes, por diversas transformaciones geopolíticas y demográficas desde la Colonia a la República, en las que por un amplio período fue administrada por misiones de la Iglesia católica, específicamente las órdenes de franciscanos y capuchinos (Bonilla, 1968), lo cual afectó la organización social de los pueblos indígenas que la habitaban. En consecuencia, las tradiciones ingas no se pueden entender solamente como las de un pueblo circunscrito al territorio del Estado colombiano -lectura que invisibiliza su pasado y tradiciones más allá de los límites nacionales que se establecieron apenas entre los siglos XIX y XX-, sino que se debe contextualizar saltando las fronteras modernas, reconociendo la herencia de la cultural andina.

El valle de Sibundoy es una zona geográfica ubicada entre la selva amazónica y las montañas de los Andes (piedemonte amazónico), por lo que allí se han generado diversas interacciones, en las que destacan redes comerciales entre diferentes grupos indígenas tanto amazónicos como andinos. Un registro señala que "durante los siglos XVII y XVIII, los grupos que habitaban la región eran los quillacinga de la montańa, los sucumbios, los mocoa y los andaki" (Ramírez de Jara, 1996, p. 113). En la actualidad, además de los ingas, esta región es habitada por los pueblos "Kamëntsá, Siona, Cofán y Murui" (Ramírez de Jara, 1996), los cuales mantienen intercambios comerciales y culturales desde hace siglos. Asimismo, el piedemonte en el que habitan los ingas se establece como un territorio fronterizo en la administración política colombiana, con difícil acceso debido a sus características orográficas.

Durante el periodo colonial, su "característica primordial es el de no ser ni independiente de los colonizadores espańoles ni tampoco sujeto a ellos en forma permanente" (Ramírez de Jara, 1996, p. 123). Los ingas que comparten el valle de Sibundoy con otras comunidades encontraron una manera de evadir el proceso colonial aislándose entre la montańa y la selva. Lo cierto, sin embargo, es que esta región fue un territorio en disputa entre Ecuador y Colombia en su proceso de división territorial acaecida durante casi todo el siglo XIX; incluso fue afectada por parte de los caucheros peruanos y brasileros que explotaron la selva en su búsqueda del caucho como producto de exportación. No es sino hasta finales del siglo XIX que la región se empieza a explorar de forma sistemática por parte de las misiones católicas y al establecerse mecanismos administrativos que transforman la vida de los pueblos indígenas ubicados en ella.

\section{Los ingas en el siglo XIX y XX. Transformación de los procesos de vida}

La relación del pueblo inga con el Estado colombiano pasa por la organización administrativa territorial de este entre los siglos XIX y XX, a lo cual se suman las normas que el Estado colombiano fue creando para establecer una relación con los pueblos indígenas que se encontraban en su territorio. Estas normas fueron hechas desde un Estado con influencias éticas y morales católicas; de forma indirecta, esto puede constatarse por la cesión de la administración de los llamados 'territorios nacionales' a la Iglesia católica desde el Estado. Específicamente para la región del Putumayo, esta administración se llevó a cabo por medio de las misiones de la Orden de los hermanos menores capuchinos en el Caquetá y Putumayo, la cual se desarrolló entre 1893 y 1929 (Bonilla, 1968; Ramírez de Jara y Urrea, 1996).

La presencia administrativa de las misiones se presentó como parte de los cambios constitucionales del país en 1886. Desde entonces, Colombia se declara como un país abiertamente confesional; ${ }^{6}$ de ahí que la única religión considerada y admitida como fundamento de la

6 Encomendado como base fundamental al Sagrado Corazón de Jesús. 
república haya sido la religión católica, motivo por el cual la Iglesia tiene predominio en la educación escolar y universitaria, así como explica su cercana relación con el Estado a lo largo del siglo XX. Esta administración de la Iglesia católica se fundamentó, principalmente, en la evangelización de los pueblos indígenas que habitaban el territorio. En 1887, el Estado colombiano firmó el Concordato con la Santa Sede, ${ }^{7}$ por medio del cual el gobierno protegía a la Iglesia católica en sus propiedades y su ejercicio. Después de la firma del Concordato se establecieron varios otros convenios entre esta y el Estado colombiano, entre ellos el llamado Convenio de Misiones de $1902 .{ }^{8}$ Estos convenios otorgaban el poder a la Iglesia para determinar las relaciones políticas de los habitantes de los territorios, que eran pueblos indígenas, quienes fueron considerados menores de edad por la Constitución y necesitaban tutela de un tercero para sus actividades civiles (Restrepo, 2006, p. 159), tercero que durante largo tiempo fue la misma Iglesia católica.

La propia Iglesia católica determinaba la condición de "indio salvaje" o "indio civilizado"; por ejemplo, la forma de vestir, hablar español y "en general, [hacer parte de] las actividades económicas establecidas allí por los 'blancos'; ligadas éstas, claro está, a las redes económicas interregionales e internacionales" (Gómez, 2005, p. 53). En el valle de Sibundoy, en los internados para menores, los padres capuchinos buscaron imponer sus normas, esencialmente a través de un tipo de vestimenta, ya que el control del cuerpo era algo primordial para la dominación del ser ejercida por los curas capuchinos. A los hombres ingas se les impuso un corte de cabello a la altura de las orejas y a las mujeres se le recortaba a la altura de los hombros, haciéndoles perder sus largas y preciadas cabelleras. Es decir, además de la dominación del cuerpo, los ingas, como a otros pueblos indígenas, fueron sometidos por diferentes tipos de violencia - tanto física como epistémica- por parte de los misioneros a través de varias estrategias:

[...] la policía sacaba a los "falibles" de la selva y, para que no huyeran, los amarraba en la escuela y a los padres que escondían a sus hijos para que no asistieran al plantel se les retenía en los cepos "hasta que prometieran mejoría”. Las sanciones fueron más allá, y quienes se resistían a ir al centro educativo, además del látigo, eran víctimas de uno de los más humillantes castigos, como culturalmente lo era entre los indígenas del valle la pérdida de su cabellera (Gómez, 2005, p. 71).

Del mismo modo, en cuanto a las prendas de vestir, los misioneros comprendieron que el "despojo de los collares de chaquiras, que adornan el cuello de los indios, era para éstos una de las sanciones y castigos más degradantes y ofensivos" (Gómez, 2005, p. 72), ya que esta ornamenta era una muestra de estatus entre la comunidad, por lo cual se prohibió su uso (Bonilla, 1968; Gómez, 2005). De esta manera, desde finales del siglo XIX y principios del XX persistió la discriminación en forma de prohibición o de burlas sobre la vestimenta indígena por parte de los misioneros. Dicha represión perduró a lo largo del siglo XX y fue ejercida por algunos colonos que arribaron al valle de Sibundoy, quienes solían mofarse de la vestimenta inga, lo que dio como resultado la paulatina eliminación del uso cotidiano de esa vestimenta. Según lo

7 Firmado entre León XIII y el presidente de la República de Colombia, Rafael Núñez. En 1886 la constitución supuso una victoria de los principios conservadores unidos a la Iglesia después de la expulsión de los jesuitas del país en 1850, de lo que se conocía como la Nueva Granada, y en 1861 de lo que se conoció como los Estados Unidos de Colombia (Salcedo, 2004). Esta alianza y sus principios se mantienen en el país hasta 1930 formalmente en el gobierno.

8 Estipulados en leyes como la ley 89 de 1890, la ley 103 de 1890 y la ley 72 de 1892. 
que vivieron los ingas, "por las 'burliscas' los padres no nos enseñaron a los hijos e hijas a vestir la ropa propia", relata Jesusa Jacanamijoy, tejedora inga del valle de Sibundoy.

A pesar de esta discriminación histórica el pueblo inga ha mantenido parte de su forma de vestir, conservando así su identidad y sus costumbres. Dentro de estas, el chumbe se distingue por mantener su contenido simbólico sin llegar a transformarse en mero objeto utilitario. ${ }^{9}$

En la actualidad, algunas mujeres ingas que ya no se visten diariamente con su vestimenta tradicional usan el chumbe debajo de sus blusas o camisas; es decir, lo portan ocultándolo de las miradas, pero está incluido como parte de la identidad ingana.

Ahora bien, el pueblo inga tiene presencia en diferentes ciudades del territorio colombiano e incluso en Venezuela, emigración que señalan con orgullo ya que ellos mismos se consideran un pueblo viajero; sin embargo, la mayor parte habita en el municipio de Santiago-Manoy perteneciente al departamento del Putumayo (Figura 1).

El Censo del Departamento Nacional de Planeación -DANE- $2005^{10}$ reportó 15450 personas autorreconocidas como ingas. Es relevante mencionar que el pueblo inga es parte de los 32 pueblos indígenas colombianos declarados en vía de extinción por el gobierno desde el año $2004,{ }^{11}$ que señala el estado en que se encuentran, los motivos que los hicieron entrar en esa categoría, y las tareas del Estado colombiano para protegerlos. Los ingas son un pueblo originario con una amplia historia de vulnerabilidad en el país.

\section{La vestimenta y tradición inga}

El pueblo inga ha preservado su vestimenta tradicional (no occidental) hasta el presente, aunque no es usada de forma diaria por la mayoría. En la actualidad son pocas las personas que lo hacen, salvo en días de fiesta ${ }^{12}$ y ceremonias especiales como celebraciones en el cabildo o en tomas de yajé. ${ }^{13}$

9 Gary Urton (1998) señala que esto ocurrió con los khipus, lo cual les hizo perder su valor como elementos sintácticos y gramaticales, y solo permaneció su instrumentalización como sistema de conteo. Basado en ello, Severi (2009) discute las transformaciones de los artefactos y textiles para dar cuenta de la construcción y contenido de los sistemas de narración de los grupos amerindios, denominándolos artefactos mentales.

10 Este es el censo general más reciente de Colombia, con respecto a los pueblos indígenas. Durante el 2018 se llevó a cabo otro conteo, sin embargo, dicho reporte no presenta los datos a detalle para conocer el número de personas pertenecientes a pueblos indígenas al momento de redactar este artículo.

11 El Plan Salvaguarda del Pueblo inga parte del reconocimiento formulado por la Honorable Corte Constitucional en la Sentencia T-025 de 2004, en la cual expone la existencia de un "estado de cosas inconstitucionales" -ECI- que se verifica cuando la vulneración repetida y constante de derechos afecta a una multitud de personas [...], y cuando esta afectación obedece a problemas de orden estructural cuya solución requiere la intervención de las distintas entidades estatales" (Ministerio del Interior, 2013, p. 15).

12 Esta festividad es celebrada el domingo anterior al miércoles de ceniza y representa el inicio de un nuevo año, relacionado con tiempos de florecimiento y cosecha. Para los ingas este día es muy especial, también es llamado el Día del Perdón, kalusturrinda o Atun Puncha (Tandioy y Maffla, s.f.). Se celebra los tres días anteriores al miércoles de ceniza, período que simboliza el inicio del tiempo litúrgico cristiano como preparación a la semana santa.

13 Banisteriopsis caapi. Ayahuasca, ambihuasca o yajé, planta de uso ceremonial entre los pueblos indígenas amazónicos. 


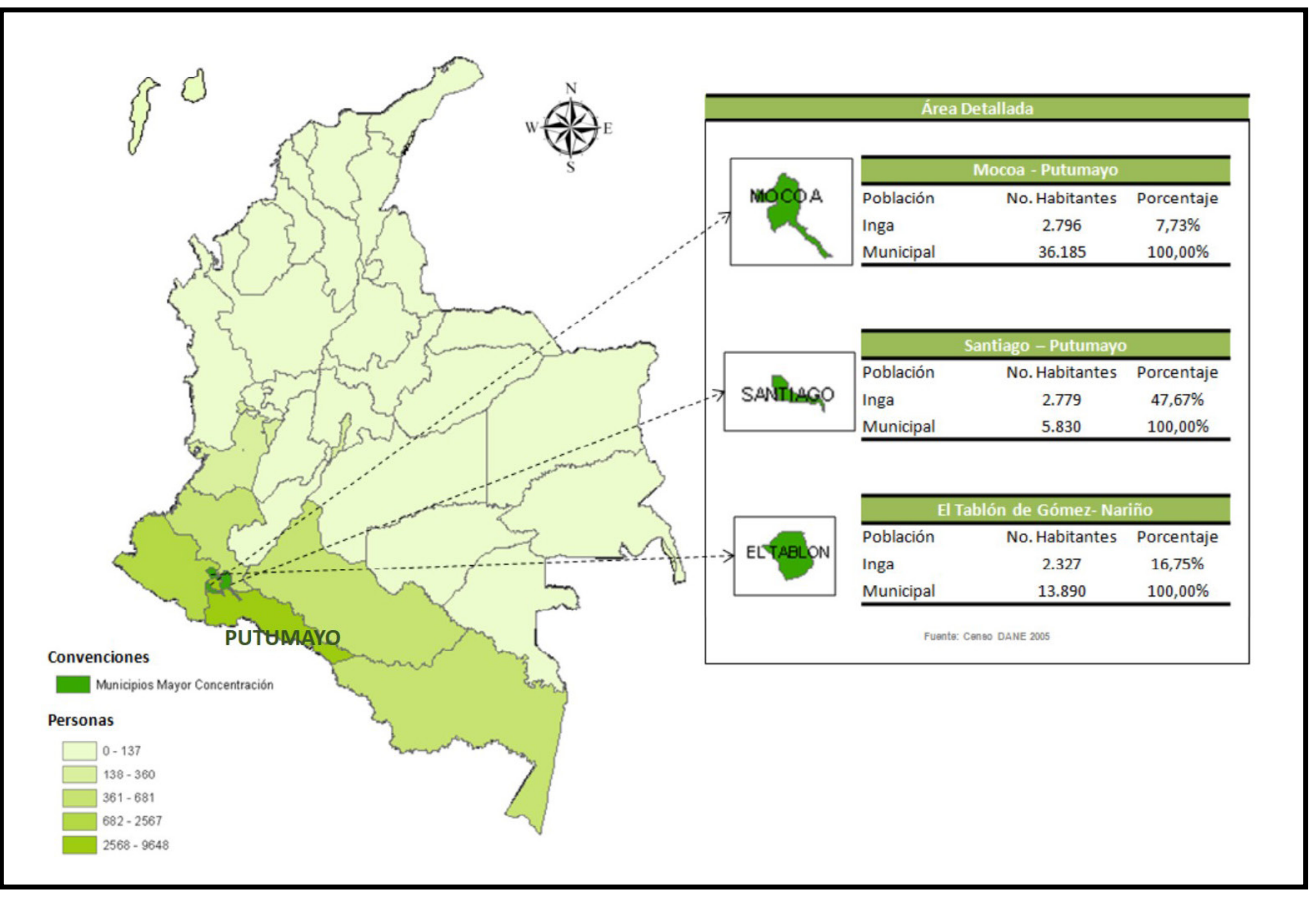

Figura 1. Ubicación de la población del pueblo inga en Colombia. Fuente: Ministerio de Cultura (2016).
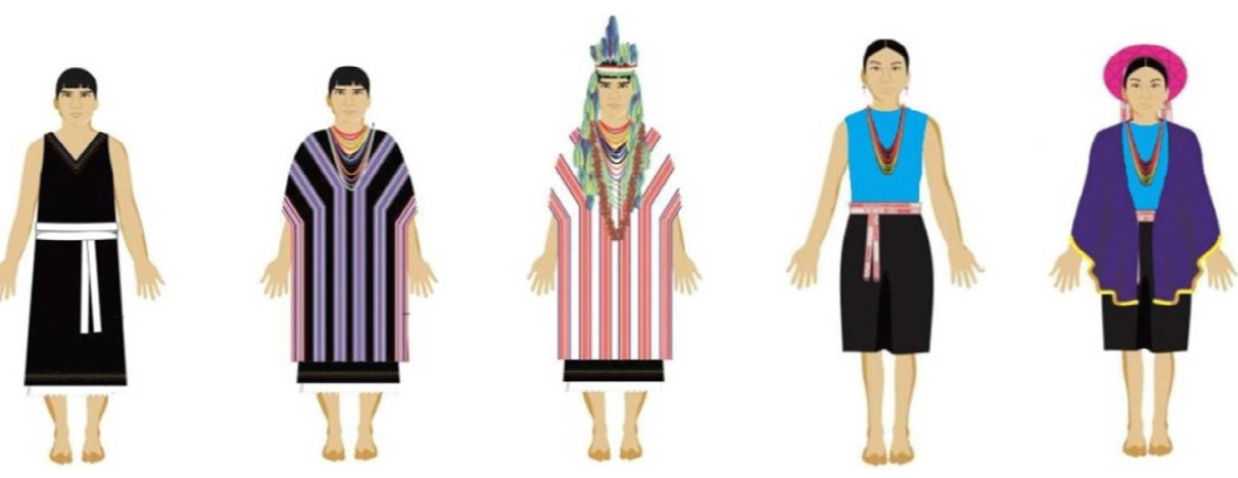

Figura 2. Vestimenta tradicional inga para hombres y mujeres. Fuente: Gómez (2012).

En la indumentaria tradicional de los ingas hay diferencias entre las prendas que portan las mujeres y los hombres (Figura 2). Estos últimos suelen utilizar La Linzo Cusma, de color blanco, que es la prenda que tiene contacto directo con la piel; la Cusma, una bata negra que llega hasta la rodilla y se pone por encima de la Linzo Cusma. Ambas se ajustan en la cintura con el Ciñidor, que es una faja blanca de entre 10 y 12 centímetros de ancho y hasta un metro de largo. Finalmente, portan el Sayo o Capisayo (ruana, poncho, capa), de color blanco con líneas rojas, o negro con líneas azules. Por su parte, las mujeres visten el Tupuye (blusa), fabricado con telas de diversos colores (azul, negro, amarillo, rojo, entre otros); la Pacha $^{14}$ (falda), que

14 Pacha tiene varias acepciones; en este caso significa 'manto' y es el mismo vocablo usado para hablar del manto de la tierra, la pacha mama. 
es ceñida en la zona del vientre por el chumbe (faja); la Baita (rebozo) que puede ser de varios colores, en telas brillantes y vistosas. Cuando se utiliza la vestimenta para una festividad, se incluyen las gualcas (collares de chaquiras) y los llagtu (coronas con plumas y cintillas atadas a la misma corona). Para el uso diario, algunos varones solo portan el capisayo y las mujeres la baita y el chumbe (muchas veces debajo de la ropa) omitiendo el resto de las prendas mencionadas de la indumentaria.

Como ya se ha explicado, chumbe es una manera de llamar a las fajas usadas por algunos pueblos indígenas. Para los ingas, como descendientes quechuahablantes, sus tejidos tienen relación con los de otros pueblos quechuas que habitan regiones de los territorios que hoy conforman el Perú, Ecuador, Bolivia y Colombia.

Aparte del chumbe, hay varios tipos de fajas en otras regiones de América, las cuales tienen diferentes denominaciones: "chumpi en idioma quechua, waka en aymara, wathraku en el quechua local del valle sur del Mantaro, sierra central, y "faja" o "cintura" en la sierra norteña del Perú" (Del Solar, 2016). El Trariwe mapuche es otra de las muestras de este tipo de tejido, así como el Challpi wathraku (de mujeres) y challpi whathrku (de hombres) de los wanka ${ }^{15}$ del actual Perú, que son de las fajas que más tradición y colorido mantienen. En la región del sur de Colombia, en comunidades ubicadas geográficamente cerca de los ingas, se encuentran otras variedades de fajas también: el chumbe paéz, guambiano y el tsombiach kamëntsa; con este último se guarda especial cercanía en los pictogramas usados por las tejedoras ingas. ${ }^{16}$ Además, para los ingas existe la faja que es de uso exclusivo del varón: el ciñidor, completamente blanco y de alrededor de un metro y medio de largo (Figura 2). Pese a que el chumbe suele ser de uso exclusivo de las mujeres, algunos varones, en especial jóvenes que se están formando como sabedores, ${ }^{17}$ lo utilizan de la misma forma que ellas, es decir alrededor del vientre, como símbolo de protección.

La longitud del chumbe inga puede variar según el uso que pretenda dársele. Regularmente tiene entre 3,5 y 4,5 metros de largo por $8 \mathrm{~cm}$ de ancho. El chumbe contiene una amplia variedad de labores, entre las que observamos temáticas generales relacionadas con el ser humano, la naturaleza, la ubicación espacio-temporal y elementos de uso cotidiano. Las labores y el orden en que se presentan varían de acuerdo con la tejedora que las realice o en función de lo que las personas, en su mayoría mujeres, solicitan.

La elaboración del chumbe es eminentemente una actividad de las mujeres; un conocimiento que se ha transmitido entre las ingas de forma ancestral, aunque en la actualidad también algunos varones jóvenes han aprendido el tejido. Relacionado con esto, observamos que la enseñanza del tejido se hace en la lengua propia (la explicación del proceso de urdido, los símbolos de las labores, el conteo en el paso de los hilos para formarlos, etc.), independiente de

15 Las fajas elaboradas en Viques y La Breña, del sur del valle del Mantaro en la provincia de Huancayo, Junín, Perú, fueron reconocidas como Patrimonio Cultural de la Nación en 2017.

16 Las similitudes con las otras fajas de los pueblos indígenas en la región, ubicados en el espacio geográfico que actualmente corresponde a Colombia, exceden los alcances de este escrito. Sin embargo, cabe señalar, con respecto al Tsombiach Kamëntsá, que ambos pueblos comparten muchos aspectos de su cultura, pero en estas fajas guardan diferencias en su elaboración. Las principales entre el chumbe inga, el chumbe nasa y el Tsombiach tienen que ver con los procesos y aspectos técnicos, pero, en especial, con las labores que se tejen; aunque la elaboración es similar en cuanto a las herramientas, materiales y procedimientos.

17 Este es el término usado por algunos pueblos indígenas, entre ellos mayas e ingas, para referirse a las personas que resguardan el conocimiento sobre plantas, oraciones o tradiciones de la comunidad sobre salud mental, física y espiritual, sean mujeres u hombres. 
que el castellano sea el idioma que regularmente utilizan para relacionarse con otras personas, en especial aquellos no ingas. El tejido se conecta con el uso de la lengua materna. Así lo relató la tejedora Ruby Rodríguez:

\section{[...] cuando estos tejidos los hacían en casa siempre era alguien que visitaba y está conversando hablando en nuestra lengua materna [...] es un placer hablar en nuestra lengua materna. Entonces cuando yo estoy tejiendo estoy pensando en mi lengua como si estuviera conversando [...] porque yo aqui hablo mi lengua materna en mi concien- cia pues asi es (Ruby Rodríguez, com. pers., mayo 14 de 2018).}

En la actualidad la elaboración del chumbe es una tarea que los ingas enseñan tanto en los hogares como en asociaciones sociales y en las escuelas indígenas, con el fin de reavivar, recuperar y mantener las tradiciones y formas de vestir propias, así como de generar mecanismos de comercialización de sus productos en mercados locales y nacionales. ${ }^{18}$

\section{Marco teórico}

\section{Artefacto cultural}

En este apartado discutiremos, desde aspectos teóricos y conceptuales, las características del chumbe inga como un artefacto cultural (Isava, 2009; Tavera y Johnston, 2017) y artefacto mental (Severi, 2009). Isava (2009) busca explicar, con base en Heidegger, qué hace cultural a un artefacto; su respuesta es que los artefactos considerados culturales se caracterizan por una cierta virtualidad, que es lo que él denomina espesor significante. Esta cualidad 'pone en obra' 19 la cultura en un artefacto, y de esta manera se constituyen como diferentes de otros artefactos, los cuales son conocidos como 'utensilios'.

Los artefactos son las elaboraciones materiales de los grupos humanos, que representan diversos factores y valores de su cultura, trascienden en el tiempo y pueden tener diferentes cargas simbólicas; suelen transformarse -y cambiar su significado inicial en diversos sentidos posteriores- e incluso desaparecer.

La palabra "artefacto" nombra en realidad todo objeto que es producto de la aplicación de una técnica; es decir, "artefacto" es todo aquello elaborado, producido por el ser humano. Esta denominación incluye, por tanto, herramientas, utensilios, formas del vestido, formas del habitar, pero también mitos, modas, refranes e incluso el diseńo y las diversas manifestaciones de lo que tradicionalmente se ha llamado arte (Isava, 2009: 442).

Dentro de la amplia variedad de artefactos que el ser humano crea, algunos se pueden volver utensilios comunes y otros adquieren un valor preponderante, se convierten en artefactos

18 La comercialización de los productos indígenas como artesanías es un tema relevante en todos los pueblos indígenas en la actualidad, sin embargo, supera los alcances de este escrito. Valga señalar que tiene aspectos útiles para el desarrollo económico de parte de la población, pero también es una situación de cuidado con respecto a la pérdida simbólica, precisamente, de estos artefactos.

19 A partir de esta cualidad, Isava replica e interpreta la pregunta de Heidegger sobre ¿qué hace arte al arte? El término 'poner en obra' lo usa en referencia a esa característica del arte llevada a los artefactos (para un análisis más detallado, ver Isava, 2009). 
culturales. En otras palabras, algunos artefactos tienen una diferenciación que se funda en una singularidad que les es dada por la manera de instrumentalizarse. Isava (2009) clarifica esta diferencia señalando que:

lo que en este artefacto se hace obra y opera simultáneamente es la cultura con sus innumerables presupuestos, convenciones y concepciones. Estos artefactos tienen o pueden tener, claro está, utilidad, pero ésta no agota su existencia; pueden asimismo alcanzar habitualidad, pero no al punto de reducirse a una pura materialidad (Isava, 2009, p. 443).

Desde esta perspectiva, la materialidad hace al artefacto cultural en tanto dinamiza rasgos de la cultura; si no es así, el artefacto es solo un utensilio, un objeto con su propia utilidad. Entonces, la manera en que se usa el artefacto es aquello que lo hace o no cultural, en cuyo caso "la materialidad se vuelve subsidiaria de la cultura" (Isava, 2009, p. 444). Esto lleva a Isava a observar que hay diferentes tipos de materialidad que 'ponen en obra' las características culturales de un artefacto, las cuales él llama virtualidad. Dicha virtualidad se activa porque el artefacto contiene redes de significación dentro del grupo social al que pertenece. Este es el proceso mediante el cual un objeto se vuelve un artefacto cultural; Isava (2009) lo denomina espesor significante.

Así, "el espesor significante del artefacto cultural sería [...] ese continuo referir más allá de sí mismo; [...] un referir que, en este caso, trasciende lo puramente simbólico, pero igualmente se sobrepone al 'uso' normal del objeto" (Isava, 2009, p. 448). De este modo, mientras un utensilio se define por su utilidad, un artefacto cultural lo hace "por (cor)responder a [las] redes de significación [de la cultura] y, al mismo tiempo y como consecuencia de ello, por patentizarlas" (Isava, 2009, p. 444). De tal manera que un artefacto cultural es un objeto que se erige entre otros objetos por la manera en que se presenta y contiene rasgos excepcionales que evidencian las complejas redes de significación de un grupo social específico, sea este o no un grupo indígena.

Por su parte, Tavera y Johnston (2017) seńalan que los artefactos culturales forman parte del análisis cultural de la sociología, pero que no han sido estudiados detenidamente; indican que su estudio ha permanecido a la sombra del análisis de las ideaciones y las performances, aunque en la sociología se han considerado estas tres (ideaciones, performances y artefacto culturales) como dimensiones de la cultura, ${ }^{20}$ teniendo en cuenta que son los artefactos los objetos concretos y materiales que se vinculan con las otras dos dimensiones. De modo que estos "están estrechamente vinculados con las ideaciones..., [aunque], a diferencia de las ideas, son objetos concretos y materiales... [y] pueden fomentar la identidad colectiva en torno a [...] significados compartidos" (Tavera y Johnston, 2017, p. 116). A su vez, los artefactos pueden ser parte de una performance como un factor simbólico -bastones de mando indígenas, cintas presidenciales, decoraciones festivas, máscaras, etcétera- o ser el centro de los mismos cuando un grupo de personas se apropia de ellos para desarrollar actos de carácter simbólico -embestiduras presidenciales, protestas, trofeos, algunos tipos de vestimentas, etcétera-. Tavera y Johnston (2017) señalan que, al centralizar las ideaciones o las performances en el análisis cultural, se ha dicho

20 Tradicionalmente el análisis cultural se fundamenta en tres dimensiones de la cultura: las ideaciones (valores, creencias, representaciones sociales, etc.); las performances (es decir, cómo se llevan a la acción las ideaciones); y los artefactos (fragmentos funerarios, objetos simbólicos, vestuario propio, etc.) (Tavera y Johnston, 2017). 
poco sobre la importancia de los artefactos culturales y la información cultural que se puede obtener y analizar del grupo social que los crea, utiliza y reproduce.

Tavera y Johnston (2017) concluyen que el artefacto cultural se destaca por el proceso temporal en el que un objeto se convierte en artefacto, la diversidad de interpretaciones que lo rodean y su redefinición multifacética. ${ }^{21}$ Para observar la materialidad de dichos procesos, Tavera y Johnston (2017) proponen observar tres categorías de un artefacto cultural: producción, arraigo social y la manera de responder frente a él por parte del público que lo usa. Sumadas al análisis de Isava (2009), se puede decir que estas categorías serían mecanismos para evidenciar el espesor significante de un artefacto cultural, aquellos aspectos que se sobreponen al uso normal del objeto y lo hacen ostentar la cultura en sí mismo.

Para observar estas características en el chumbe, en el presente análisis se entiende por producción los procesos básicos de elaboración del artefacto, es decir, los materiales y las herramientas necesarios para su obtención. Por arraigo social se entiende el afianzamiento y permanencia que tiene el artefacto cultural, que se evidencian en su enseñanza y en las transformaciones o adaptaciones que experimenta. Y, en cuanto a la manera como el público responde a él, se entiende aquí los significados e interpretaciones que se le han otorgado a nivel personal y grupal, y los que se han hecho a nivel material y simbólico. En estos tres aspectos confluyen las características que hacen del chumbe un artefacto cultural.

\section{Artefacto mental}

Para complementar la categoría de artefacto cultural, se usa la propuesta de Severi (2009) en relación con las características mentales de un artefacto. El autor señala que hay ciertos artefactos de los pueblos amerindios que son "artes de la memoria" y, en esa medida, son artefactos mentales. La característica principal de este tipo de artefactos es que en ellos el ejercicio de la memoria y el uso de signos gráficos no están disociados, lo cual es una muestra de que contienen tres clases de relaciones: de tipo mnemónico, de tipo iconográfico y de tipo lógico. De acuerdo con Severi (2009), la asociación de los signos gráficos y los procesos memorísticos que contienen los artefactos mentales son dos elementos que condensan un sistema de conocimiento compartido, expresado a través del establecimiento de un orden y una preeminencia que diferencia las categorías de ese sistema.

Entonces, las "artes de la memoria" amerindias, en tanto artefactos mentales:

[...] suponen tres operaciones constitutivas. Una selección de las palabras a representar, la construcción de una preeminencia ${ }^{22}$ visual y el establecimiento de un espacio ordenado que toma la forma de una sucesión de transformaciones de una forma geométrica de base donde aparecen temas visuales, cada uno con su especificidad. Estas operaciones se unen de manera inmediata a formas de enunciación del saber tradicional (Severi, 2009, pp. 472-473).

21 Agregan a esta definición una cuarta característica relacionada con la posibilidad de ser usados y cobrar sentido dentro de una movilización social.

22 Aquí usamos el sustantivo preeminencia, pero el término en francés el autor usa saillance que es un neologismo y que hace referencia a ser destacado o sobresalir de una cosa en relación a otras. Está relacionado con el verbo saillir y el sustantivo saillante. 
A través de estas tres operaciones se generan relaciones entre los elementos representados, las formas en que se plasman y aquello que representan en el saber del pueblo indígena. Las formas representadas condensan diferentes aspectos de la cultura y, en esa medida, les permiten ser usados como elementos mnemónicos de la cosmovisión. Entonces, la categoría "mental" del artefacto, de acuerdo con Severi, comprende la selección de las palabras a representar, la construcción de la preeminencia visual y el establecimiento del espacio ordenado; categorías entre las cuales se establecen varios tipos de relaciones entre el dominio de la lengua y la representación icónica.

Para observar estas características en el chumbe, la selección de palabras se debe interpretar como el proceso de discriminación de algunos conceptos por sobre otros, los cuales se convierten en una labor del chumbe. Se entiende por preeminencia visual las características de contraste que se generan entre los pictogramas del tejido por medio del uso del color, de formas y de materiales, y que hacen que las labores sean llamativas, significativas diferenciables entre sí. Y, finalmente, se entiende el espacio ordenado como la elaboración de cada labor bajo dos aspectos: un proceso memorístico que permite a la tejedora aprenderla y repetirla, conocer sus errores y hacerle variaciones sin cambiar su forma elemental; y el reconocimiento del contenido simbólico iconográfico que cada labor contiene. En estos tres aspectos confluyen las características que hacen del chumbe un artefacto mental.

Para comprender el carácter de artefacto mental del chumbe, es primordial especificar lo que significan sus labores. Como anteriormente señalamos, las ingas llaman labores a cada una de las figuras simbólicas que se tejen en el chumbe. Son figuras simbólicas porque representan diferentes temáticas ${ }^{23}$ de la cosmovisión inga por medio de formas geométricas, y contienen la característica de permitir "el ejercicio de la memoria y el uso de signos gráficos" (Severi, 2009, p. 466). En este artículo las denominamos pictogramas, de acuerdo a la propuesta de Severi (2009) según el cual los pictogramas plasmados en los artefactos mentales no son comparables con dibujos o historias:

[...] su apariencia no tiene nada de "realista" y los elementos gráficos que le constituyen pueden señalar relaciones (de inversión, de prolongamiento, de inclusión, de analogía, etc.) [...] solo por la vía iconográfica. En tanto que grafismo, el pictograma supone una iconografía coherente y un saber definido (Severi, 2009, p. 473).

En efecto, las labores son elementos gráficos que suponen un saber definido, en este caso la cosmovisión del pueblo inga, y que expresan este saber por medio de su elaboración y el contenido simbólico de cada una de ellas.

De esta manera, entendemos que las labores muestran, por una parte, las operaciones mentales que supone el conjunto de conocimientos ingas y, por otra, la tradición iconográfica desde la cual se construyen formas geométricas a partir de varios niveles (mnemónico, iconográfico y lógico) que dan cuenta de dicho conocimiento.

23 Como las que aparecen en la columna de 'Labores/Pictogramas' de la Tabla 1. 


\section{Estrategia metodológica y herramientas de investigación}

En cuanto a la metodología, este trabajo está basado en tres herramientas fundamentales: la entrevista semiestructurada a profundidad, realizada a tejedoras del chumbe y taitas sabedores del pueblo inga; el análisis visual de 25 chumbes antiguos y modernos, y el registro fotodocumental -desde una perspectiva de la sociología visual- del chumbe y los pictogramas que contiene. No obstante, la investigación de los chumbes elaborados por el pueblo inga se analizó durante dos años previos al trabajo de campo, a través de imágenes digitales, archivo de hallazgos audiovisuales y resultados de investigaciones académicas.

El trabajo de campo lo realizamos durante una visita al municipio de Santiago-Manoy durante 10 semanas en el año 2018. En ese período realizamos 12 entrevistas a tejedoras, sabedores y un especialista sobre al tema de los chumbes e historia inga; todos ellos, a través de sus experiencias y de sus narraciones, explicaron los significados del chumbe, así como detalles de su proceso de elaboración y preservación del saber de los ingas.

Las entrevistas fueron respaldadas con la observación y participación en la elaboración del chumbe. Al mismo tiempo se observaron y analizaron chumbes antiguos, algunos con más de 80 años, lo cual permitió corroborar en detalle los pictogramas de chumbes antiguos y modernos. Por su parte, el registro fotodocumental desde una perspectiva de la sociología visual se usó como un recurso alternativo para la recolección de información que, en este caso, permite narrar visualmente este tejido.

La sociología visual ha construido su propia tradición a partir de trabajos de análisis apoyados en el uso de la cámara fotográfica, imágenes impresas, videograbaciones y registros visuales en general, los que son analizados a partir de una observación minuciosa y con un trasfondo teórico. En ese sentido, en el presente artículo la observación es considerada como un "registro sistemático de fenómenos o comportamientos observables en un entorno natural" (Gorman y Clayton, 2005, p. 40). Este tipo de observación tiene como núcleo los referentes del trabajo de campo que aportan los hallazgos visuales (Banks, 2001). En otros términos, las imágenes son una cartografía que dota de contenido y guía al trabajo analítico, estimula una narrativa de la teoría visual y mantiene vivas las memorias que se recogen de un hecho específico de la realidad social. Esto justifica la relevancia de incluir elementos visuales en el trabajo de investigación sociológica.

De esta manera, mientras se desarrollaron las entrevistas, se hizo una elección de las imágenes del chumbe y de su elaboración para complementar las evidencias de esta investigación, en concordancia con el marco teórico elegido. El posterior análisis de los hallazgos consistió en realizar un entrelazamiento de las entrevistas, el marco teórico y el archivo fotográfico obtenido en el trabajo de campo. Las imágenes se analizaron en correspondencia con los datos verbales y el registro del diario de campo para hacer con esta dinámica un triple registro documental: lo expresado (registro del discurso por medio de las entrevistas en profundidad), lo observado (registro de la acción con ayuda del diario de campo) y lo visual (registro fotográfico). 


\section{Hallazgos}

\section{El chumbe inga como artefacto cultural}

\section{La producción del chumbe}

Las mujeres ingas elaboran el chumbe utilizando técnicas ancestrales de tejido heredadas por sus antepasados. Antiguamente se utilizaba solo el telar de cintura, pero en la actualidad combinan esta técnica con el telar vertical llamado guanga (Figura 3), que en promedio mide $1.0 \times 1.50 \mathrm{~m}$.

Para tejer el chumbe primero se prepara la urdimbre: este proceso se realiza mediante diferentes métodos de acuerdo a si se va a tejer en telar de cintura o en la guanga. En el primer caso se clavan cuatro o cinco palos en el piso o sobre una base de madera, dispuestos en forma de rombo (los cuales cumplen la misma función de $\operatorname{los}_{\text {enjullos }}{ }^{24} \mathrm{y}$ las varas de paso) para facilitar el cruce de los hilos. Si se hace en la guanga, el proceso es el mismo, pero se usan los travesaños superior e inferior del telar como enjullos y se atan palos divisores a uno de los laterales del telar (que van a ser la varas de paso). El urdido se hace en forma de "C" (con el principio y el fin unidos en una misma vara, lo cual simula un tejido en "O"25). En ambos casos se cuida de mantener los hilos con la misma tensión y distribuir los colores uniformemente. En la actualidad se privilegia el urdido directo en la guanga.

El largo de la urdimbre depende de la dimensión del tejido que se va a elaborar. Se utilizan hilos de lana (natural o sintética) y se escogen dos o tres colores, que son distribuidos a lo ancho del urdido. Los hilos se urden en una forma muy compacta, quedando muy unidos. Los colores se intercalan en una estructura de faz de urdimbre y resaltan en los motivos de la labor. Así, se selecciona un color de fondo (urdimbre inferior), otro para tejer las labores (urdimbre superior) y, si se quiere, un tercer color para los bordes. En esta etapa se tiene mucho cuidado del proceso de intercalado de los colores por medio de las varas de paso, que van a servir para separar los hilos y formar las labores.

En caso de hacer el tejido en telar de cintura, después de urdir y elegir los planos en urdimbre superior y urdimbre inferior, se enlazan los extremos a los palos de amarre, uno de los cuales se ata a un gancho que se sostiene de la pared, o se amarra de un árbol o columna, y el otro extremo se ata a un lazo que se amarra alrededor de la cadera de la tejedora. En caso de mantener el uso de la guanga, solo se sueltan las varas de paso (atadas a uno de los laterales) y se ajustan entre sí en relación con el travesaño central (que une el inicio y fin de la urdimbre). De esta manera se inicia el tejido.

Para comenzar el tejido, primero se eligen los hilos pares, con los cuales se realizarán las labores, y se anudan con una hilaza blanca que se va a constituir en alzadera (urdimbre superior).

24 Varas de madera que sostienen y sirven de tensores en el tejido en la parte superior e inferior de este.

25 Se amarra el hilo en un travesaño intermedio que sirve como inicio y final y luego se pasa hacia arriba hasta el travesaño superior y por detrás; después se baja hasta el travesaño inferior, envolviéndolo para repetir la acción a la inversa desde el comienzo y terminar en el travesańo central; este va a permanecer como parte del tejido hasta terminarlo. Este tipo de urdimbre permite que al avanzar en la labor el tejido se deslice entre los enjullos y la tejedora pueda bajar fácilmente la urdimbre para continuar con él. Al terminar la confección, la tejedora suelta el travesaño central y se estira el chumbe. 


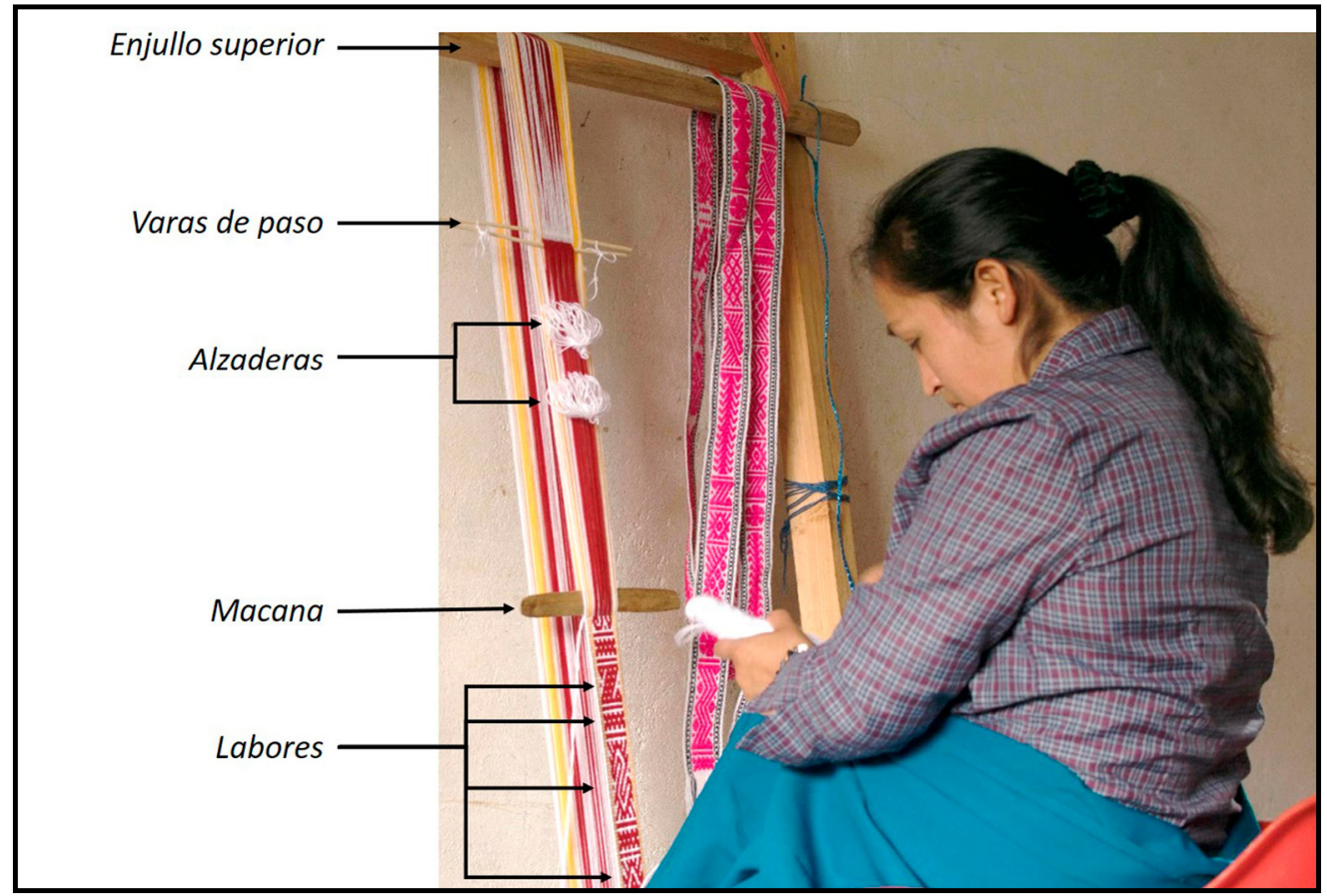

Figura 3. La producción del chumbe. Tejedora de chumbe en su guanga. Fuente: Archivo de los autores.

El segundo paso consiste en la elección de los hilos impares, los que se anudan con otra hilaza blanca por encima de la anterior para conformar la urdimbre inferior o zona lisa. Al finalizar la separación del urdido se dejan entre 10 y $12 \mathrm{~cm}$, desde el inicio de la urdimbre, y se hace una cadeneta para la alineación inicial del tejido. Acto seguido, se da comienzo al proceso de tejido con un hilo que constituirá la trama, el cual no queda visible y es indispensable para sujetar los hilos de la urdimbre y formar las labores, las que se forman a partir de una estructura de faz de urdimbre. De esta manera, este hilo es el que delimita los bordes del chumbe (ver Figura 3). Por lo general en el chumbe pueden tejerse alrededor de 20 o 30 labores, dependiendo de las que elija la tejedora.

En la elaboración del chumbe se utilizan, además, diferentes herramientas de madera, como las varas de paso que comúnmente son palos de helechillo ${ }^{26}$ o de verbena, ${ }^{27}$ las cuales se usan para formar la calada. Para apretar cada pasada del hilo con que se trama, se usa la macana, tradicionalmente hecha de palma de chonta, ${ }^{28}$ una pieza de madera que tiene bordes muy finos y que permite compactar el tejido y posibilitar el paso del ovillo de lana al momento de tejer.

Durante el proceso de tejido, permanentemente se cuidan los orillos (bordes) para que el chumbe no se cierre y se deforme. Este determina la calidad de la faja y revela la experticia de la tejedora. Cuando se ha terminado la última labor del chumbe, los hilos del final se dejan del mismo largo que los del inicio, y se cierra el tejido con la técnica de cadeneta para el remate final y alineación. Con los hilos sueltos del inicio y el final se hace trenzado entrecruzando los dedos en técnica de lazos por grupos de hilos.

26 Una variedad de Dicksonia antarctica.

27 Verbena officinalis. De esta se aprovecha, ya que su tallo se ramifica en trifurcaciones.

28 Bactris gasipaes. 
Este intrincado proceso lo realizan las mujeres ingas en la confección de las fajas que utilizan para sostener sus pachas o, en la actualidad, debajo de su ropa. Esta producción hace de un objeto como la faja un artefacto cultural. En consecuencia, el chumbe durante su elaboración adquiere lo que Isava (2009) llamó virtualidad, caracterizándose como un objeto que va a condensar en sí las redes de significación de la cultura inga.

\section{El arraigo social del chumbe}

El arraigo de un artefacto, de acuerdo con Tavera y Johnston (2017), se observa por su afianzamiento y permanencia. En el caso del chumbe inga, estos atributos se evidencian en las diferentes formas de utilizarlo, la enseńanza de su confección y transformaciones o adaptaciones. En cuanto a su uso, se trata de una prenda de vestir de uso diario que ha permanecido en las mujeres del pueblo inga desde tiempos prehispánicos, usada como faja que adorna y protege el vientre, para envolver a los bebés recién nacidos y portarlos, y como elemento que permite cargar objetos.

Por otra parte, el chumbe puede ser considerado como una "prenda menor" por su pequeño tamaño y su poca o nula visibilidad, ya que, como señalamos, en la actualidad hay mujeres que lo portan debajo de su ropa. Sin embargo, para los ingas el chumbe no es solo una faja, sino "un elemento que protege el vientre de la mujer" (Jacanamijoy, 2014, p. 213). Esta zona específica del cuerpo, según los ingas, es el punto donde se inicia la vida y, por lo tanto, debe ser protegido de forma primordial. La continuidad de uso es relevante porque pueden reemplazarse otros elementos de la indumentaria tradicional, no así el chumbe, ya que es utilizado por las mujeres para sostener el vientre desde la niñez hasta la edad adulta: el uigsa uarmi (vientre de mujer) o uigsa suyu (lugar del vientre) que se simboliza por medio de un rombo dividido en cuatro partes iguales (Figura 4). Para la cultura inga el vientre es el lugar de vida, "Uigsa Suyu", lugar donde se inicia la vida o mundo -lugar de los cuatro puntos cardinales- (Jacanamijoy, 2017, p. 72).

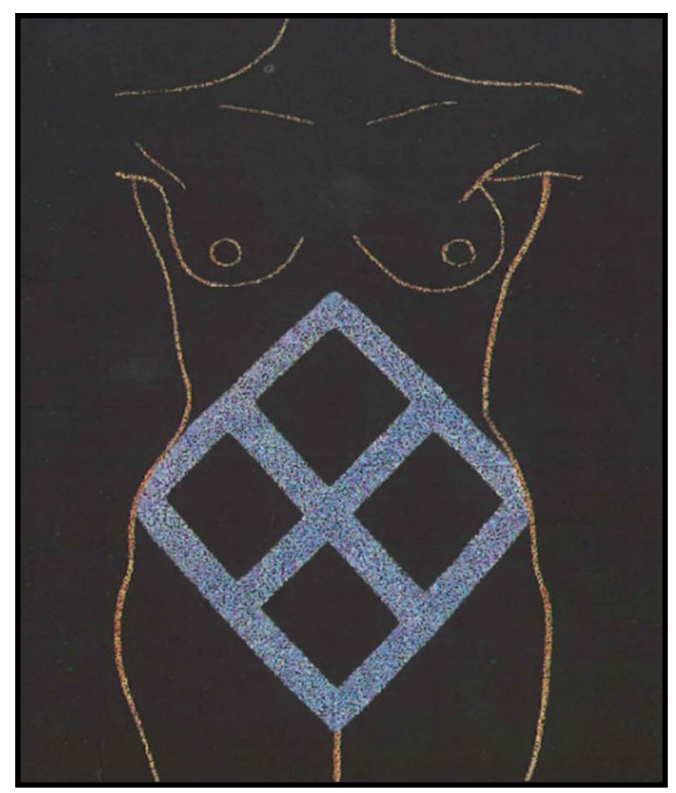

Figura 4. Terminología del chumbe. Suyu kallarij. Uigsa Suyu.

Lugar en donde todo se inicia, lugar del vientre. Fuente: Jacanamijoy, 2017. 
Aunque esta práctica no es tan frecuente en la actualidad, el chumbe también se usa como faja para envolver a los bebés recién nacidos y hasta aproximadamente su sexto mes de vida, pues los ingas aducen que da fortaleza ósea y espiritual. Del mismo modo, se utiliza como una especie de lazo para cargar a los niños de meses de edad. Para ese efecto, se envuelve en "el cuerpo del pequeño, cruzándolo por la espalda y el tórax de la madre [lo cual crea] un lazo maternal mediado por el uso del chumbe como elemento unificador y de identidad de la relación familiar" (Baena, 1998, p. 24). Esto permite a la madre tener libertad de movimientos para hacer otras tareas, a la vez que mantiene un lazo de cercanía con el menor. Al respecto, las tejedoras entrevistadas indicaron la importancia del uso del chumbe para la mujer y para envolver a los infantes recién nacidos:

Cuando pasa la dieta [del embarazo] a veces a las muchachas les crece la barriga, quedan barrigoncitas, entonces para que no les crezca el estómago y no se jodan la cintura, entonces se fajan en esto y les endura el hueso porque el hueso siempre queda débil, ¿sí? De pronto en el hospital que le llegan a tener el bebé nunca lo utilizan, pero por lo mismo queda débil [...]. A mis hijos [cuando eran bebés] a todos les fajé con esto, y ahorita [...] no son enfermos ni nada por el estilo, digamos tienen fuerza para poder cargar (Jesusa Jacanamijoy, com. pers., mayo de 2018).

Como herramienta de carga el chumbe tiene un valor actual e histórico. Se encuentra documentado que los ingas sirvieron como cargueros para algunos colonizadores, especialmente en el servicio a los curas capuchinos cuando estos llegaron a la región a principios del siglo XX. En este caso el chumbe se amarra en sus extremos para soportar cierta carga pasándolo por encima de la cabeza del porteador (Figura 5). Este método de carga se utiliza también con los saparros ${ }^{29}$ para la recolección en la cosecha.

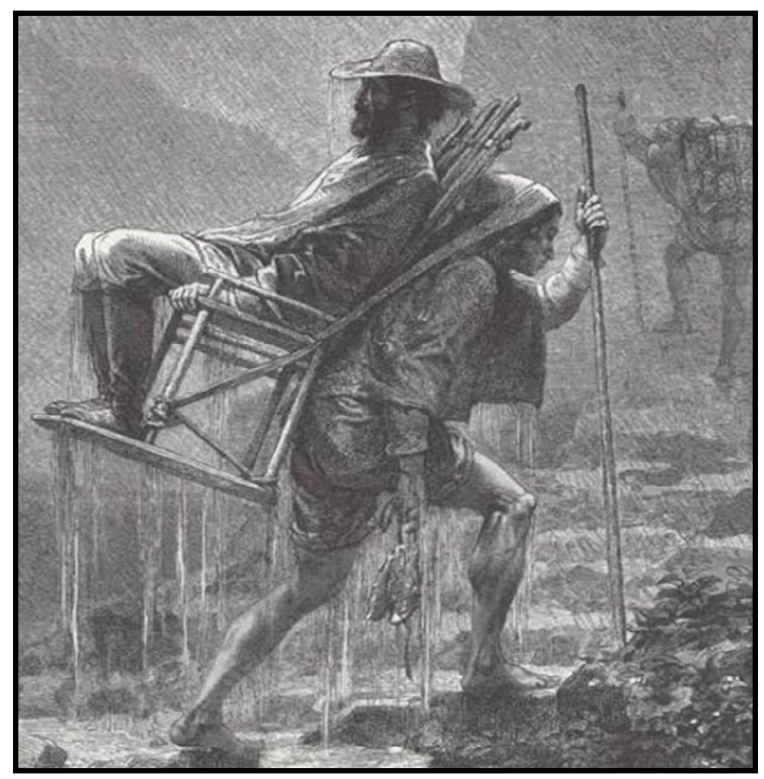

Figura 5. Arraigo del chumbe. Usos. Cargueros Indígenas. Monte de la agonía. Geografia Pintoresca de Colombia, viaje de Edouard André, 1861. Fuente: Gutiérrez (2011).

29 Los saparros son los canastos o cestas de tamańo grande elaborados con fibras vegetales. 
En cuanto a la permanencia del chumbe, esta se verifica por medio de su enseñanza y por las transformaciones o su adaptación. Como ya se ha mencionado, la enseñanza del tejido del chumbe es una tarea femenina, cuyo conocimiento se ha transmitido entre las mujeres ingas de forma ancestral, aunque en la actualidad también varones jóvenes lo han adquirido e, incluso, algunos lo portan como una manera de "volver a conectar con la raíz" (Pablo Tisoy, com. pers., abril 24 de 2018). Se enseña su confección en el ámbito familiar, y en la actualidad también en la escuela indígena ${ }^{30} \mathrm{y}$ en asociaciones civiles de la misma comunidad que buscan mantener y recuperar la identidad propia. Como nos relató una tejedora:

Yo más he enseñado [...] para no perder nuestra tradición [...] y lo hago con mucho cariño porque digo algún día tiene que seguir esto. No quiero que se acabe esto, ¿no? O que sea solamente historia o que sean en dibujos que queden, sino que siempre estén los tejidos ahi y que sepan lo que están haciendo los tejidos [...] porque también estamos en amenaza de que tenemos que ser historia, eso es lo importante digo. Mientras estemos presentes siempre que haiga presente y siempre lo desde antes que nunca se acabe (Ruby Rodríguez, com. pers., mayo 3 de 2018).

Además de su elaboración, se enseña el significado de los pictogramas, y, en especial, la comprensión y memorización del proceso de tejido para que cada pictograma tenga una forma específica y detallada. Las tejedoras expertas pueden llegar a modificar o adornar más las labores, lo cual se pudo observar en los chumbes antiguos y en aquellos elaborados por mujeres mayores y expertas, habilidad que no manejan aún las tejedoras recién iniciadas. De esa manera, se relata y transfiere el conocimiento que ha sobrevivido a varias generaciones.

Por otra parte, las labores del chumbe han sido transformadas o se han empezado a aplicar en otros objetos, en especial con el fin de darles un uso comercial-artesanal. Esto se evidencia, por ejemplo, en el tejido de manillas y collares con chaquiras, en el tejido de mochilas (Figura 6), e incluso se han incorporado en los sayos de hombres, los cuales, regularmente, solo tienen líneas rectas en su tejido.

\section{La respuesta del público frente al chumbe}

Aparte de los usos cotidianos o tradicionales del chumbe inga, un rasgo de la manera en que el público responde al chumbe inga se evidencia en su interpretación como un medio para contar historias, que no tiene el mismo sentido gramatical ni semántico de la lengua escrita, la cual obedece a la normativa de los idiomas europeos impuestos a los pueblos amerindios.

Los ingas consideran que el chumbe es un elemento que puede contener historias descritas por medio de cada una de sus labores. Las tejedoras describen estas "historias" usando los pictogramas como referencia a su entorno geográfico. Para comprender este tipo de herencia narrativa se debe tener en cuenta que la oralidad inga está intermediada por los pictogramas que están plasmados como labores, son una representación visual que permite tanto contar historias como organizar el mundo, lo cual es una tradición del mundo andino (Severi, 2009). Por ejemplo, al describir la labor del río (Figura 7), una tejedora nos relató:

30 En Santiago-Manoy se enseña el tejido del chumbe como clases de 'arte' en la Escuela Inga Iachai Wasi Carlos Tamabioy. Estas clases son parte de su proyecto educativo institucional. 


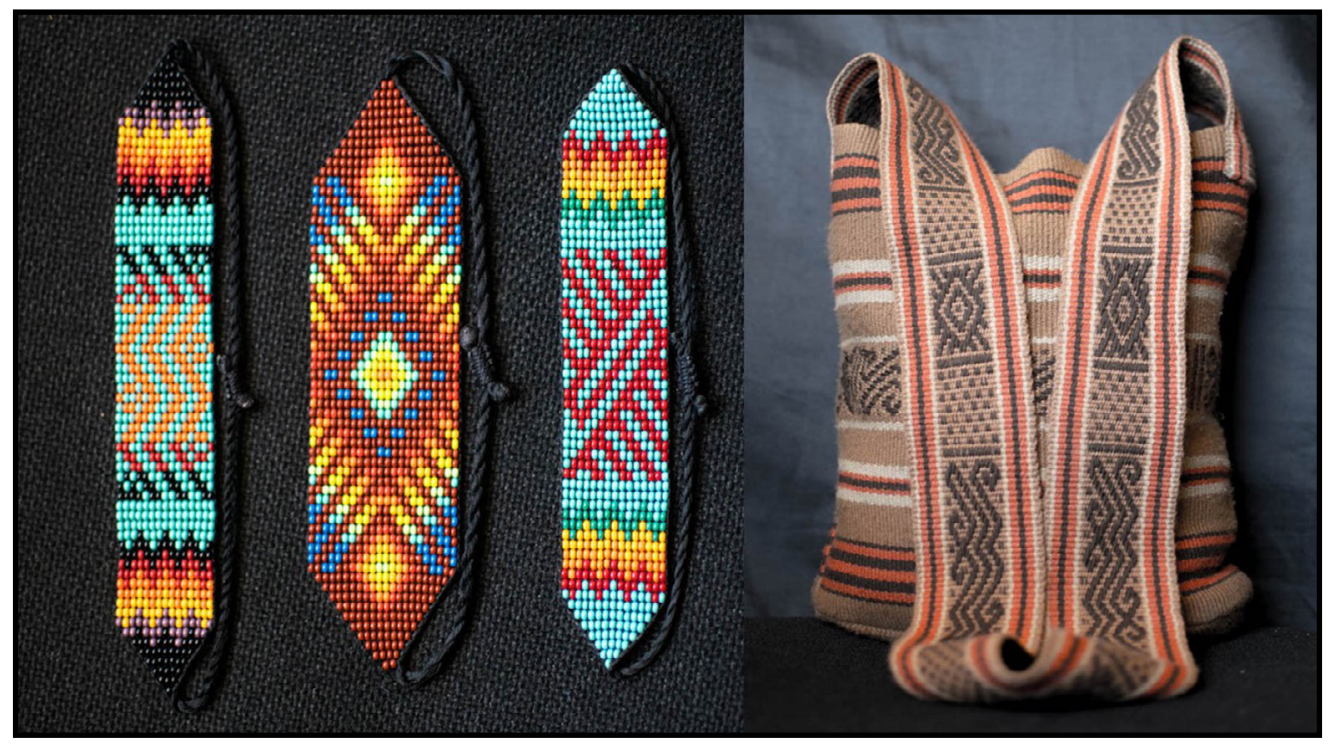

Figura 6. Adaptación de las labores del chumbe en manillas de chaquira y en mochilas. Fuente: Archivo de los autores.

Esta figura en mi mente me hace pensar en que sale agua de un lado y sale otra agua de otro lado, viene, chocan donde chispea [...]. Yo escucho el ruido cuando ellos chocan. Yo quisiera que tener una casa cerca del rio donde escucharlo en horas de la mañana, en el día, quisiera despertar a medianoche [...]. Eso es lo que yo pienso cuando estoy elaborando las figuras en nuestras prendas de vestir (Ruby Rodríguez, com. pers., mayo de 2018).

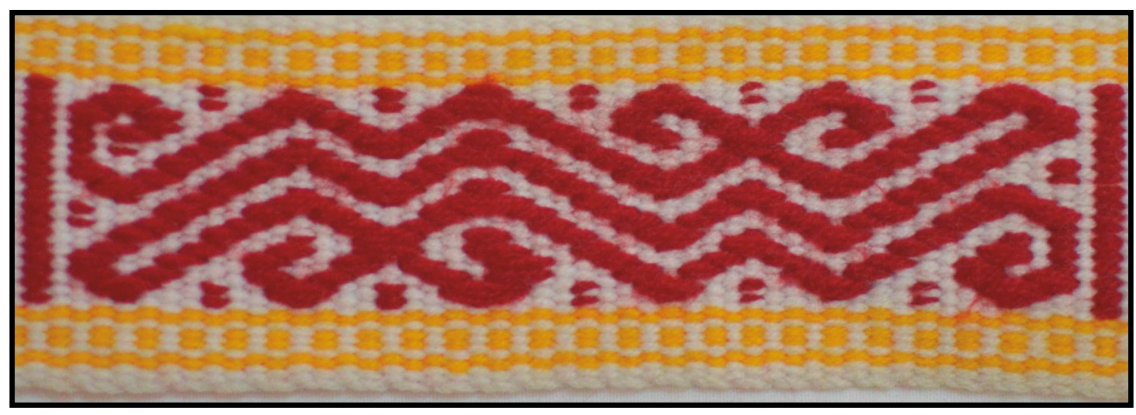

Figura 7. La respuesta del público frente al chumbe. Labor del río. Mirada horizontal. Fuente: Archivo de los autores.

Es decir, cada figura evoca la memoria y el sentir de la tejedora y de quien lo porta. Al investigar las labores del chumbe y los significados e interpretaciones que le da el pueblo inga, se observa que "detrás de los diseños de los tejidos hay siempre un pensamiento más general sobre la cultura, detrás del cual subyace un sistema que da cuenta de él” (Cereceda, 2011, p. 181).

Efectivamente, en los textiles de los pueblos indígenas se expresa un tipo de código comunicativo que expresa la forma de pensar, de vivir y de sentir el entorno en el que se encuentran, 
así como su identidad y las relaciones que establece el pueblo con el tejido. Erróneamente los estudios de herencia europea consideran que la escritura del alfabeto grecolatino es un punto de inflexión para que desaparecieran los pictogramas de las culturas originarias que no tenían un sistema de escritura como el europeo (Severi, 2009). Esta tradición supone que las letras son la única manera de expresar la posibilidad narrativa de un pueblo. No obstante, en el caso del chumbe inga, las tejedoras usan los símbolos que contienen las labores como un lenguaje propio; lo usan para narrar historias (Jacanamijoy, 2014, 2017).

La estructura narrativa del chumbe guarda un orden diferente al occidental, no es sistemático, sino como "artes de la memoria" (Severi, 2009) en la que cada labor es un hito para contar, para narrar una historia, una frase o un pensamiento que habla de la vida y del entorno inga; por lo tanto, cada relato de un chumbe puede variar de acuerdo con la manera de observar sus labores. "Este ejercicio de lectura y escritura mediante los diseños de las tejedoras es una forma poética para describir el lugar de vida" (Jacanamijoy, 2017, p. 214); una poesía que tiene cadencia desde la sensibilidad de la lengua inga y su herencia quechuahablante.

Asimismo, el orden en que se tejen cada una de las labores tiene, según los relatos de las tejedoras, un significado. El chumbe puede comenzar a "leerse" por cada uno de los extremos. En otros términos: se desenvuelve y va 'hilando' las historias, relatos concatenados, visiones e interpretaciones de los lugares y de las experiencias. De esta manera, como nos lo relató la tejedora Ruby Rodríguez, "cada chumbe es una historia" (Rodríguez, com. pers., mayo de 2018). El chumbe es una especie de rollo fotográfico en negativo. Cuando el 'negativo' se observaba a contraluz podían distinguirse las imágenes de una historia general en caso de que el rollo utilizado correspondiera, por ejemplo, a fotografías de una fiesta. De tal modo que las labores de manera aislada representan un significado, pero en la concatenación a lo largo del chumbe, estas adquieren un nuevo sentido a manera de historia.

Entonces, se interpreta el chumbe como artefacto cultural gracias a su proceso de elaboración ligado a la identidad inga, sus enseńanzas y su cosmovisión. Del mismo modo, por su arraigo social que permite su permanencia y afianzamiento en su uso, además de la innovación en otras aplicaciones y combinaciones, razones por las cuales se amplía la gama de posibilidades de su permanencia. Finalmente, el chumbe es un artefacto cultural porque se le han dado varias interpretaciones en su uso como prenda de vestir y herramienta de trabajo, pero también, como una herramienta para contar historias, para unir pensamientos y así interpretar el entorno con el cual tienen contacto los integrantes del pueblo inga que habitan el valle de Sibundoy. Estas tres características como artefacto cultural se van a profundizar y ampliar con su análisis como artefacto mental, a continuación.

\section{El chumbe inga como artefacto mental}

\section{La selección de las palabras para convertirse en labores}

Hay diferentes aspectos que han determinado las palabras que quedaron como labores del chumbe. En la revisión de las labores de los 25 chumbes que se analizaron, se encontró que las palabras relacionan cuatro temáticas generales: el ser humano; elementos de la naturaleza; conceptos la ubicación espacio-temporal y elementos de uso cotidiano (Tabla 1). 
Tabla 1. Labores en el chumbe.

\begin{tabular}{|c|c|c|c|}
\hline Temática general & Temática específica & Labor/pictograma & Nombre en español \\
\hline \multirow[t]{8}{*}{ El ser humano } & \multirow{3}{*}{ Mujer } & Uarmi & La mujer \\
\hline & & Uigsa uarmi & El vientre de la mujer \\
\hline & & Uarmi uaua & La niña \\
\hline & \multirow{2}{*}{ Hombre } & Kari & El hombre \\
\hline & & Uigsa kari & El vientre del hombre \\
\hline & \multirow[b]{2}{*}{ Familia } & Ayllu & La familia \\
\hline & & Uigsa tujtu & $\begin{array}{c}\text { Mujer embarazada } \\
\text { (flor de vientre, el embarazo). }\end{array}$ \\
\hline & Comportamiento & Kauachij sujpa ñaui & Máscara (falsedad) \\
\hline \multirow{14}{*}{$\begin{array}{l}\text { Entorno de la } \\
\text { naturaleza }\end{array}$} & \multirow{5}{*}{ Geografía } & Atun Yako & El río grande \\
\hline & & Uchulla yako & El río pequeño \\
\hline & & Arco iris & $\mathrm{El}$ arcoíris \\
\hline & & Sacha & La montaña \\
\hline & & Yako & El agua \\
\hline & \multirow{4}{*}{ Animales } & Mojojoy & La rana \\
\hline & & Kindi & El colibrí \\
\hline & & Kutisinamam purij & El cangrejo \\
\hline & & Mariposa & La mariposa \\
\hline & \multirow{3}{*}{ Flores } & Tujtu & La flor \\
\hline & & Cachos de venado & Cachos de venado, planta \\
\hline & & Uicundu & Bromelia, planta \\
\hline & \multirow{2}{*}{ Alimentos } & Uirru & El maíz \\
\hline & & Patsha hakiug kukitu & costilla de gallina (coles) \\
\hline
\end{tabular}




\begin{tabular}{|c|c|c|c|}
\hline \multirow{19}{*}{$\begin{array}{l}\text { Ubicación } \\
\text { espacio-temporal }\end{array}$} & \multirow{3}{*}{$\begin{array}{l}\text { Lugares hechos por el } \\
\text { hombre }\end{array}$} & Chagra suyu & La chagra \\
\hline & & Ñambikuna suyu & Los caminos \\
\hline & & Suyu kuna & Los lugares \\
\hline & \multirow{6}{*}{ Nociones mentales } & Kaugsay suyu & Lugar de vida \\
\hline & & Samai suyu & Lugar de los sueños \\
\hline & & Puncha suyu & Lugar de día \\
\hline & & Tuta suyu & Lugar de noche \\
\hline & & Samai suyu & Lugar espiritual \\
\hline & & Samai & $\begin{array}{l}\text { Aliento/conocimiento/ } \\
\text { espíritu/sueńo }\end{array}$ \\
\hline & \multirow{6}{*}{$\begin{array}{l}\text { Medición de } \\
\text { momentos de vida }\end{array}$} & Kutij & El tiempo \\
\hline & & Sugllasina kutijkuna & Tiempos iguales \\
\hline & & Sugsina kutijkuna & Tiempos diferentes \\
\hline & & Kutijkuna Ayllu Uigsama & Tiempo de familia \\
\hline & & Uigsa ñaui & Dar a luz (ojos de vientre) \\
\hline & & Uigsa suyu uañuj & La muerte \\
\hline & \multirow{4}{*}{ Astronomía } & Inti & El sol \\
\hline & & Nagcha & Venus \\
\hline & & Chaska & Estrella \\
\hline & & Chaska ñauimurukuna & Ojos de estrella \\
\hline \multirow{5}{*}{$\begin{array}{l}\text { Elementos de uso } \\
\text { cotidiano }\end{array}$} & \multirow{3}{*}{ Elementos del hogar } & Banco & El banco de pensar \\
\hline & & Saparro & El canasto \\
\hline & & Flauta & La flauta \\
\hline & \multirow{2}{*}{ Elementos de fiesta } & Ramus & El ramo \\
\hline & & Llajtu & El plumaje \\
\hline
\end{tabular}

Fuente: Elaboración propia a partir del análisis de chumbes e información de las entrevistas. 
Los pictogramas son geométricos y tienen como base principal el rombo. Llegamos a observar 46 labores diferentes ${ }^{31}$ (ver Tabla 1). No obstante, las personas entrevistadas nos comentaron que algunas de las labores que veían en chumbes antiguos ya no se encuentran en la actualidad. En este sentido, una tejedora relató que "[...] pues esta cinta es de mi mamá, ¿no? De antes [...] pero entonces ya están viejitas ¿no? Yo la guardo pues por recuerdo y porque tienen unas figuras bien bonitas que ahora en las figuras no se ven, que es como de hilo o de algodón, pero se nota que son más bonitas, entonces las tengo aqui (Elena Jansasoy, com. pers., junio de 2018).

Con respecto a la desaparición de estas labores, podemos constatar dos maneras de este fenómeno: la primera es cuando permanece el pictograma, pero su significado no se conoce; la segunda, cuando se recuerdan labores vistas en chumbes antiguos, pero estas ya no se elaboran ni se conoce su significado. En el primer caso, la desaparición alude a su significado y en el segundo tanto a su significado como a su forma iconográfica de representación.

Los pictogramas hacen referencia a actividades y elementos cotidianos con los cuales los ingas se relacionan, ya que para los ingas "[e]l mundo se entiende como un solo gran territorio, subdividido a su vez en una infinidad de lugares de vida y pensamiento; por lo tanto, cada lugar se constituye en un espacio de convivencia e intercambio de conocimientos" (Jacanamijoy, 2017, p. 22).

Dentro de este contexto, en el pensamiento inga se usa el vocablo suyu para expresar la ubicación en lugares: kaugsay suyu (lugar de vida), puncha suyu (lugar de día), tuta suyu (lugar de noche), chagra suyu (lugar de chagra), entre otros (Jacanamijoy, 2017). Cada lugar puede ser representado en una labor del chumbe, de tal manera que las palabras que representan el entorno geográfico quedan plasmadas en el tejido. Vale decir, las labores del chumbe no son fortuitas ni están desconectadas de la vida inga o de los objetos de su entorno:

[...] por ejemplo a veces uno lo hace "solamente yo tejo, yo pongo las labores aqui nomás", pero no es eso, lo que es del tejido como inga [...] digamos, lo que es en la chagra hay todas las cosas que son típicas y lo que estoy dibujando aqui lo tengo que tener sembrado, lo que yo puedo brindar a mis hijos y todo eso, que de pronto a veces algunos no lo piensan como inga, si no "bueno, yo siembro porque siembro o tejo porque tejo", no es eso ¿si? Entonces, lo que es la comida sagrada, digamos, lo tengo acá también [en el chumbe] y lo que es la sanación como es también (Jesusa Jacanamijoy, com. pers., mayo de 2018).

Los lugares y la manera de expresarlos, sin embargo, no hacen referencia solo al mundo material (objetos o espacios) sino también a las emociones y sensaciones que la interacción con los objetos y lugares puede transmitir. Otro de estos suyus es el mismo "lugar" del cuerpo humano, es decir, el lugar que ocupa la corporalidad:

[1] os conocimientos llegan al cerebro a través del corazón y posteriormente salen convertidos en palabras de saber o samai: aliento transmitido desde lo más profundo del ser. El estómago es, a su vez, el Kaugsay suyu kallarij: lugar de vida de quien comienza, que en el caso de la mujer es el espacio primordial en donde se inicia la vida. En ese lugar se guardan los sentimientos más intimos del ser humano (Jacanamijoy, 2017, p. 56).

31 No significa esto que no existan más. Estas son las que pudimos observar con nombres y con imágenes de acuerdo a los chumbes observados. 
De tal manera que algunas partes del cuerpo tienen una interpretación comparable con la tierra o Pachamama, en especial cuando los ingas hacen referencia a la chagra. El resguardo de la vida, además de tener una vinculación directa con el vientre femenino, se encuentra relacionado con la chagra (lugar de cultivo). Los ingas relacionan la chagra con el vientre de la Alpa o Pacha Mama; para ellos, tanto la mujer como la tierra son la madre que da vida. La chagra también tiene su propia labor en el chumbe (Figura 8), símbolo que representa el lugar para el cultivo, donde se reúne la familia; es el punto del hogar donde se mantiene la tradición de las semillas, la continuidad de la vida, la obtención del alimento, es decir, el lugar donde se obtiene el sustento para la familia.

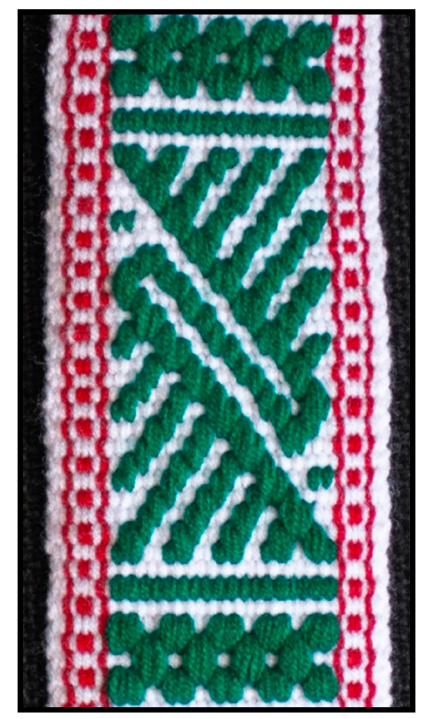

Figura 8. Terminología del chumbe. Elementos de la naturaleza: la chagra. Fuente: Archivo de los autores.

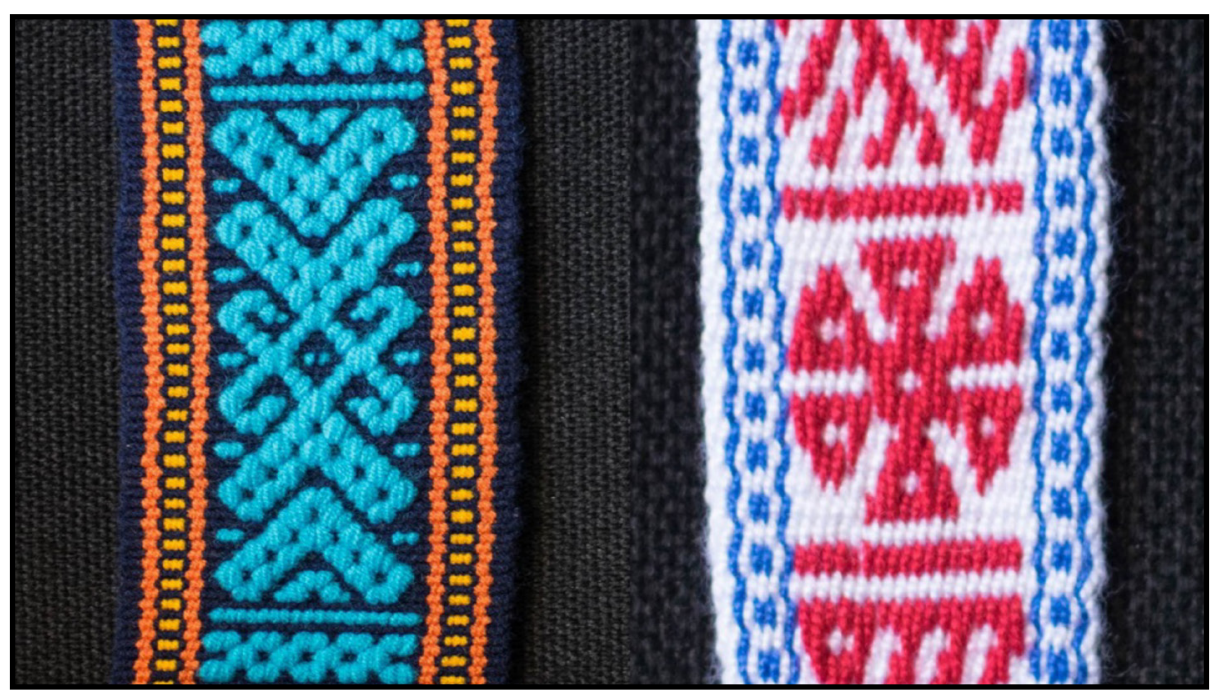

Figura 9. Terminología del chumbe. Elementos de la naturaleza.

Flores: Uicundu (bromelia). Tujtu (hortensia). Fuente: Archivo de los autores. 
En los conceptos relacionados con la naturaleza también están las flores y los alimentos. En la Figura 9, por ejemplo, en el lado izquierdo se encuentra la flor bromelia (Uicundu) y en el lado derecho, la flor de Atun Puncha (Tujtu). ${ }^{32}$

Con respecto a los elementos de la naturaleza, una tejedora nos comentó su perspectiva acerca de su elección a ser plasmada en el tejido:

En la faja lo que más utilizamos es las figuras que tiene [...] la chagra [ver Figura 7], lo que es de nuestros ancestros, lo que es el sol, lo que es de nosotros mismos... la familia. [...] Tenemos el ojo, pues el significado del ojo es en agradecimiento a Jesús porque nosotros siempre decimos... mi mamá sabia decirme: "un granito de frijol, un granito de maiz que siembre es el ojo de Dios" Entonces, nosotros lo sembramos aqui y siempre lo tenemos (Jesusa Jacanamijoy, com. pers., mayo de 2018).

Las labores que hacen referencia a la ubicación espacio-temporal, por ejemplo, el tiempo (Figura 10), se combinan con labores de tiempos iguales o tiempos diferentes (Jacanamijoy, 2017); esto se refiere a la cosmovisión de los quechuahablantes. Por ejemplo, si dos personas comparten un momento (caminar juntos), a esto se le denominaría 'tiempos iguales'; y en cambio se dice 'tiempos diferentes' cuando una persona se separa o fallece.

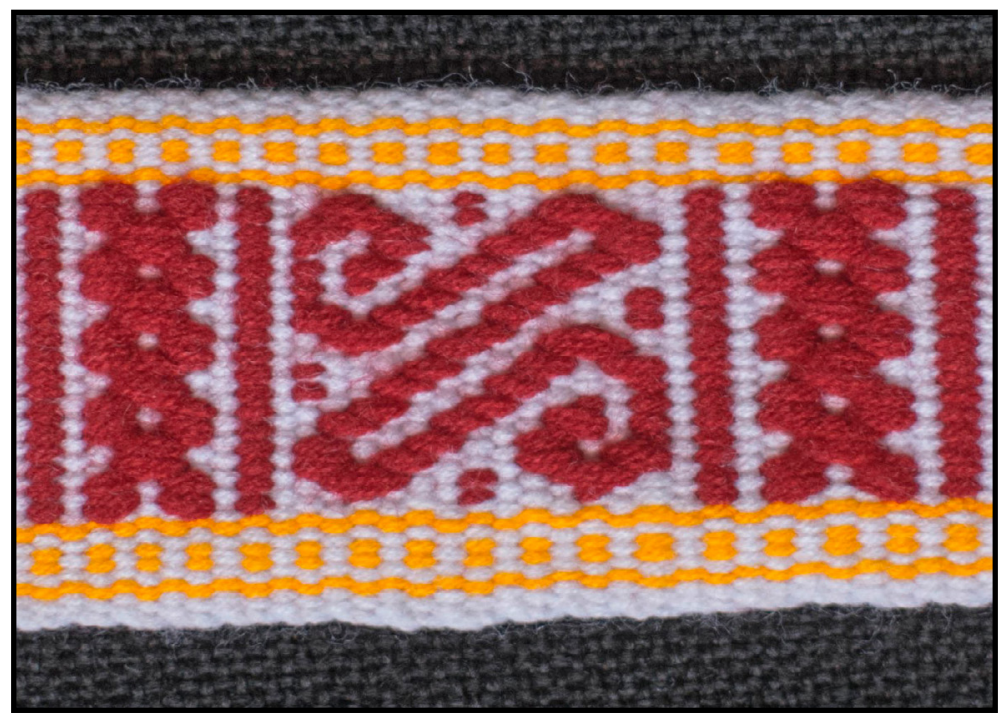

Figura 10. Conceptos del chumbe. Cosmovisión. El tiempo. Kutij. Fuente: Archivo de los autores.

Las labores del tiempo también se complementan con símbolos de la muerte (tiempo de muerte), los caminos o los lugares. Estas labores se concatenan de modo tal que los símbolos van construyendo historias en el chumbe. Una imagen de ello, a manera de ejemplo, es cuando se hace la labor del símbolo del tiempo y enseguida se relaciona con el símbolo del hombre; se cuenta como el momento por el cual el hombre transita, puede ser un tiempo de alegría por las fiestas (enlazando el vientre con la flor de carnaval), o el tiempo de cosecha (enlazando el

32 Tujtu traduce flor en general, y hay varias maneras de realizar la labor. 
pictograma del tiempo con el de la chagra). Con la elección de las palabras para convertirse en labores, mediante su potencia y expresividad, se pueden apreciar los niveles de relaciones iconográficas y lógicas, que muestran el orden cosmológico del pueblo inga (Severi, 2009); características con las cuales el chumbe demuestra su condición de artefacto mental.

\section{La preeminencia visual de las labores del chumbe}

El contraste de colores y de texturas de las labores del chumbe es una característica visualmente estética. Con la elección de los colores se inicia esta diferenciación: aquellos que van a conformar la parte del fondo (urdimbre) deben contrastar con las labores. Tradicionalmente el color de fondo es el blanco; y rojo, verde, negro o amarillo el de las labores. Antes, los hilos eran de algodón o de lana, y las mismas tejedoras realizaban el proceso de tinturado. De acuerdo a los relatos de las entrevistas, los ingas tenían la costumbre de tinturar los hilos con elementos vegetales como achiote, barro, algunas flores, etcétera. Sin embargo, esta tradición se ha perdido porque los materiales usados son sintéticos. En la actualidad, aparte de los colores más tradicionales, se hacen chumbes de fondo azul, beige o verde claro y las labores pueden ser en color fucsia, rosado, naranja, morado (Figura 11), y las lanas que se usan son, casi siempre, sintéticas. En cuanto al uso de colores, podemos apreciar que estos poseen un significado para los ingas: el verde tiene relación con el entorno natural; el azul, con la humildad; el rosado, rojo y fucsia con la alegría; el morado y el negro con la tierra. Y el blanco, con el perdón (Artesanías de Colombia, 2017; información recolectada en trabajo de campo).

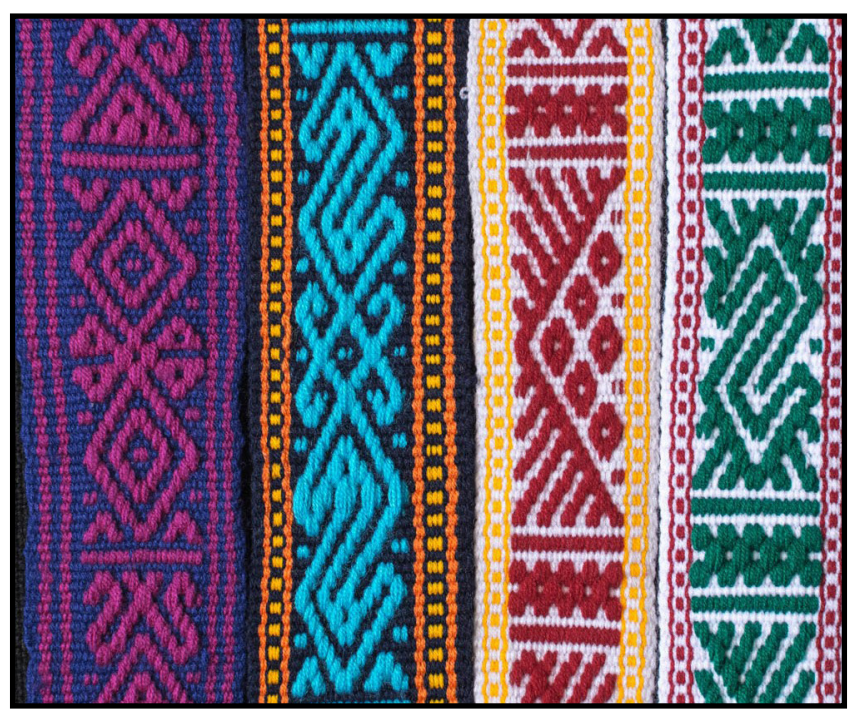

Figura 11. Preeminencia visual. Expresividad en el chumbe. Fuente: Archivo de los autores.

La preeminencia visual empieza con la elección de los colores para las labores y continúa con la cantidad de hilos, que pueden ser del mismo grosor que los del fondo o mayor, con el fin de constituir relieves en el artefacto. Y aquí es importante recordar a Severi (2009), quien señala que para la observación de las características de un artefacto mental se deben analizar, más que los materiales, las “operaciones mentales y de relaciones entre iconografía y lenguaje" (p. 478), puesto que esto es lo que indica la potencia y expresividad del sistema de símbolos que sostienen los pictogramas. 
Así, son importantes los colores y la cantidad de hilos, pero lo verdaderamente relevante es comprender la potencia lógica de los pictogramas, que le confieren expresividad gracias a que portan el conocimiento del pueblo inga. En este caso los colores le agregan un valor emocional al chumbe, pues en él también se manifiesta el carácter de quien lo teje o lo usa de acuerdo a los valores sociales que se les atribuye. De igual manera, las labores tienen una lógica que expresa la profundidad de su mensaje. En el caso del chumbe, es mayor la expresividad que tiene la faja gracias a la cualidad geométrica y el impacto visual de sus labores.

Otro rasgo de la relevancia visual es que hay labores de características externas similares, pero con diferente significado, como las que tienen de base el suyu (lugar) que, como ya mencionamos, se representa con un rombo. Como podemos observar en la Figura 12, de izquierda a derecha tenemos samai suyu (rombo con líneas diagonales) entrelazado con tujtu (flores); puncha suyu (lugar de día) entrelazado con cachos de venado; ${ }^{33}$ luego puncha suyu enlazado con tujtus; y, finalmente, un tuta suyu (lugar de noche) enlazado con tujtus. Estas labores a primera vista son iguales, pero su diferencia radica en el tipo de lugar al que hacen referencia y el momento del día en el que se pueden producir encuentros en esos lugares. Asimismo, tiene relación con encuentros familiares al estar enlazados y formar el pictograma que hace referencia al ayllu (rombos conectados por flores). Estas labores remiten a tiempos de reuniones, familias, momentos del día y unión. De esta manera, se muestra que la expresividad y la potencia lógica de las labores del chumbe no coinciden con las del lenguaje en su lógica sintáctica castellanizada (Severi, 2009) y, precisamente, en ello radica la fortaleza de las distintas cualidades del chumbe como artefacto mental: los procesos relacionados con la capacidad de evocación de cada pictograma, aspecto en el que las tejedoras, en tanto constructoras de cada labor son también las narradoras de las historias (Figura 12).

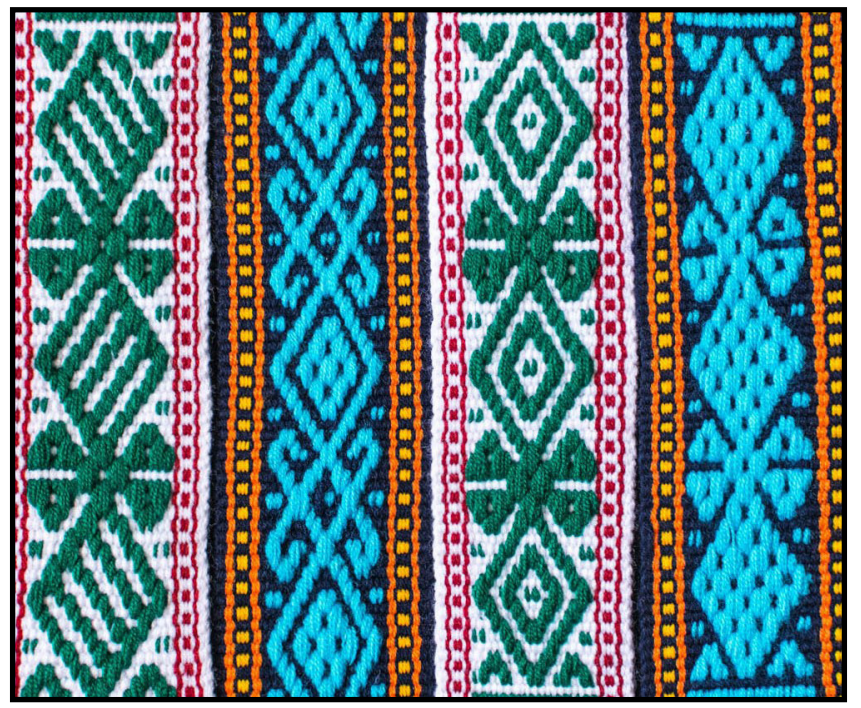

Figura 12. Preeminencia visual. Labores similares. Labores que contienen suyus. Fuente: Archivo de los autores.

33 Platycerium. Nótese que este pictograma no tiene nombre en lengua quechua. 
Otro tipo de preeminencia se presenta cuando las tejedoras realizan la misma labor con diferente diseño, por su propio gusto y estilo. A saber, en este caso se puede hablar de diferentes diseños en las labores del chumbe. En la Figura 13 se ejemplifica lo anterior con dos labores: en el lado izquierdo del pictograma del sol en dos diferentes diseńos; de la misma manera se observa en la fotografía del lado derecho en la que se muestra el símbolo de la familia en dos versiones diferentes.

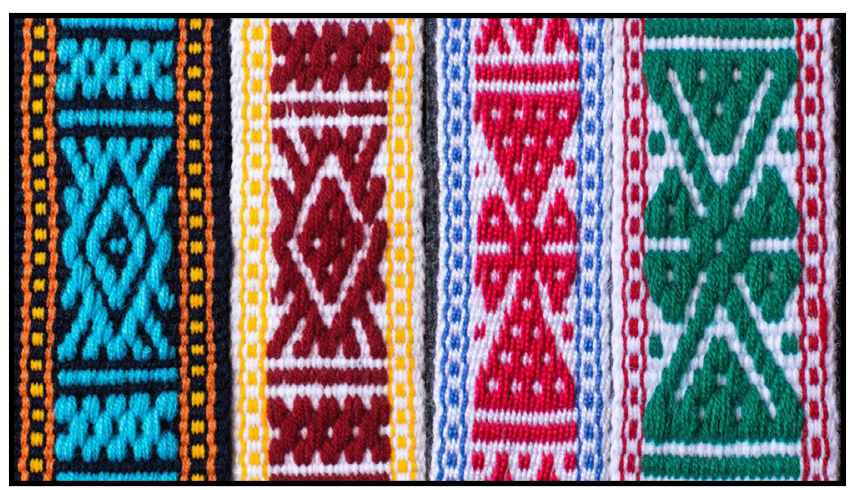

Figura 13. Preeminencia visual. Diseños diversos en las labores. El sol, Inti. La familia, Ayllu.

Fuente: Archivo de los autores.

La preeminencia visual al modificarse los diseños, como en este caso, tiene una relación de contenido y de codificación. De acuerdo a lo señalado por Severi (2009), al modificar la labor se genera una codificación mnemónica para quien construye, narra o interpreta el chumbe; a la vez que subraya que en el arte del tejido del chumbe son primordiales el estilo y la pericia de la tejedora.

\section{El establecimiento de un espacio ordenado en el tejido del chumbe}

El procedimiento detallado de elaboración de las labores del chumbe inga tiene varias características singulares. La primera es que los puntos que la componen se cuentan en pares en horizontal y en impares en vertical, por lo que se sigue que estas siempre tendrán una forma rectangular. La segunda es el cálculo numérico de los hilos; la tejedora entrelaza los hilos por pares "dibujando" la labor de abajo hacia arriba hasta formarla completamente. Cada una de estas labores ha sido memorizada por las tejedoras a través de la constante repetición de los símbolos tejidos.

El proceso de realización de las labores contiene un continuo ejercicio de memoria que incluye el cálculo matemático: el conteo constante del hilado en la urdimbre, en el paso del hilo de la trama que "forma" cada pictograma y el cruce de los hilos de las alzaderas. Este cálculo de los hilos se suma a la generación del espacio ordenado, se puede decir que en dos niveles distintos: uno con respecto a la red de significaciones de la cultura inga y otro, al orden de un pensamiento matemático y memorístico, que, una vez más, tiene que ver con la pericia de la tejedora. En ese sentido, se puede afirmar que en el chumbe los pictogramas, "como conjunto gráfico organizado para el uso mnemónico" (Severi, 2009, p. 467), tienen elementos de códigos memorísticos tanto en su elaboración como en su resultado. 


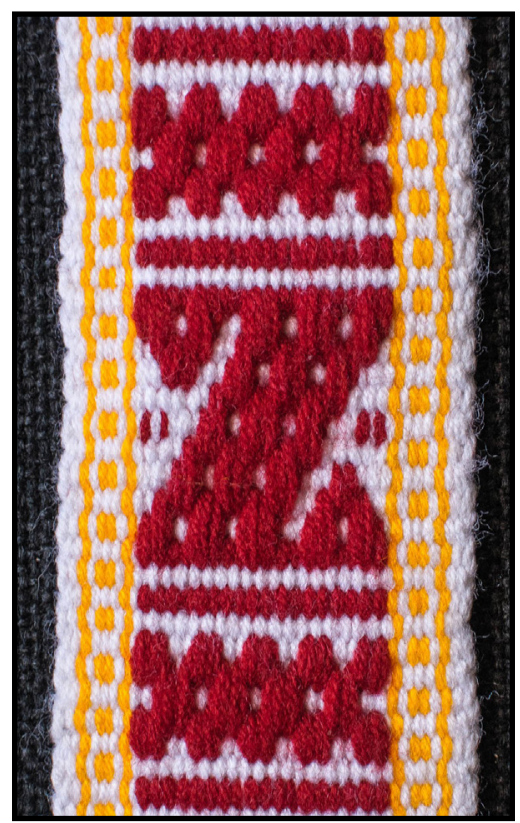

Figura 14. El espacio ordenado del chumbe. Labor del banco de pensar terminada. Fuente: Archivo de los autores.

Al terminar la labor, la división de sus partes se puede describir por puntos pares, tal como es posible observar en las Figuras 14 y 15. El olvido de un punto hace que la labor no sea prolija, lo cual nos habla del nivel de destreza de la tejedora.

\begin{tabular}{|c|c|c|c|c|c|c|c|c|c|c|c|c|}
\hline Línea 1. & & & & & & & & & & & & \\
\hline Línea 10 & & & & & & & & & & & & \\
\hline Línea 9 & & & & & & & & & & & & \\
\hline Línea 8 & & & & & & & & & & & & \\
\hline Línea 7 & & & & & & & & & & & & \\
\hline Línea 6 & & & & & & & & & & & & \\
\hline Línea 5 & & & & & & & & & & & & \\
\hline Línea 4 & & & & & & & & & & & & \\
\hline Línea 3 & & & & & & & & & & & & \\
\hline Línea 2 & & & & & & & & & & & & \\
\hline Línea 1 & & & & & & & & & & & & \\
\hline & 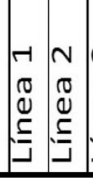 & 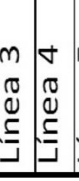 & 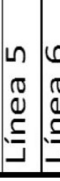 & 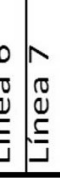 & 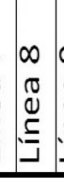 & 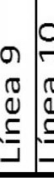 & 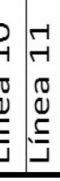 & 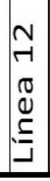 & 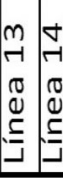 & 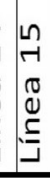 & $\mid \begin{array}{l}0 \\
-1 \\
0 \\
0 \\
0 \\
\\
\end{array}$ & 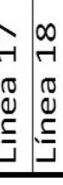 \\
\hline
\end{tabular}

Figura 15. El espacio ordenado del chumbe. Diseńo de la labor del banco de pensar por puntos. Fuente: Elaboración propia. 
Finalmente, para las tejedoras ingas el conocimiento hace parte de su saber y de su memoria. La tejedora Ruby Rodríguez lo explicó señalando que para ella este conocimiento es su pensamiento:

\begin{abstract}
Como indigena, yo agradezco mucho a Dios que nos haya dejado con esas artes, con esos pensamientos, que yo sea una persona única, que yo sepa mis saberes, que yo tenga ese pensamiento inga. Luchar, trabajar con mi pensamiento (Ruby Rodríguez, com. pers., mayo de 2018).
\end{abstract}

De esta manera, es por medio de la construcción de las labores que se presenta un doble proceso de evocación: para construir el pictograma y para recordar la codificación de la memoria que expresan las redes de significación del conocimiento inga.

El chumbe inga tiene como característica diferenciadora que en su tejido se entreveran los símbolos de actividades cotidianas que relacionan la chagra y la naturaleza, el ser humano, y el pensamiento o las creencias sobre aspectos de su vivir. Las labores guardan relación directa con los lugares de vida como parte del imaginario cotidiano que se encuentra tanto a través de la palabra como en el contexto geográfico que los rodea. La Chagra como lugar de cultivo, los ríos, la lluvia, la rana, el amanecer, la montańa, el sol, todos ellos elementos que son parte de la vida cotidiana del pueblo inga que habita el Alto Putumayo. Para los ingas la naturaleza tiene un lenguaje propio; y una vía que han encontrado para transmitirlo es a través de la simbología plasmada en el chumbe.

Por lo tanto, el chumbe es atado en el vientre no como un acto de vestir fortuito, sino como un gesto lleno de simbolismos: el vientre es cubierto con las interpretaciones de la vida y la tierra, de los frutos concebidos y engendrados en la Chagra en consagración y conjugación con la lluvia; el río lleva en sí un ritmo único que avisa a los pobladores sobre las ricas aguas que acarrea; las montańas que rodean el valle de Sibundoy son elevaciones milenarias que revelan la inmensidad de un lenguaje que no puede ser solo expresado con palabras, sino con pictogramas que cuentan y hacen pervivir la historia propia de los inga: un pueblo ligado indefectiblemente al poder de la tierra. Por ende, las labores del chumbe no podrían ir desconectadas de la vida del inga y su tierra.

De esta manera, la conexión entre el humano y su entorno es permanente, el conocimiento de la naturaleza pasa al humano y este lo devuelve en un sentido de horizontalidad constante. Este tipo de pensar se sintetiza en la filosofía de vida del pueblo inga: suma yuyay, suma kaugsay, suma rimay. Vivir bien, pensar bien, hablar bien. Algunas traducciones toman el vocablo "bien" como "bonito", probablemente porque pensar bonito y pensar lo correcto consigo mismo, con el entorno y con el otro son equivalentes para el pueblo inga.

\title{
Conclusiones: cuando se teje el chumbe inga, se teje con la mente
}

A través del desarrollo de este escrito se ha sostenido que el chumbe inga es un artefacto cultural y mental. Y es cultural por su sofisticado contenido de significaciones. Al mismo tiempo, en el chumbe inga se pueden encontrar elementos pictográficos que son una muestra de los saberes e interpretaciones de los ingas. Por medio del chumbe el pueblo inga expresa su cosmovisión y las redes de significación culturales que ha construido como grupo social. El chumbe, en tanto 'arte de la memoria' amerindio nos permite evidenciar esas construcciones de sentido de esta particular comunidad. 
Lo que hace que el chumbe pueda denominarse artefacto cultural es el proceso creativo que hay en su elaboración, su afianzamiento, permanencia, los significados e interpretaciones que los ingas le otorgan. Por su parte, las características del chumbe como artefacto mental se pueden observar al momento de la elección de las palabras que son plasmadas en cada labor, la elección de los materiales, así como las técnicas mnemónicas por medio de las cuales se construye cada labor y se evoca su contenido. Estas características mentales se despliegan en el contenido del chumbe en tanto arte de la memoria amerindio, y por lo tanto encontramos que este puede ser 'leído' con herramientas y ejercicios diferentes a los del saber occidental. Lo anterior es posible gracias a las cualidades mentales que contiene el chumbe, y son parte de un sistema de representaciones simbólicas cuya expresividad y potencia lógica no coinciden con las representaciones del sistema de lenguaje.

La primera característica cultural de este artefacto es el proceso de construcción de la faja, la preparación de los elementos y herramientas que lo hacen posible, los cuales, si bien se han transformado en el tiempo, trascienden su materialidad básica y le dan una 'virtualidad' a la faja desde el primer momento de su confección. Esta primera cualidad cultural está directamente conectada con la primera cualidad mental: la elección de las palabras que serán labores; ambos procesos se refieren a la elección de elementos que van a constituir el chumbe.

El afianzamiento y permanencia del chumbe, como su segunda característica cultural, también se encuentran ligados a la cualidad mental de este con respecto a su preeminencia visual. Esta preeminencia visual tiene que ver con la elección de colores tanto como con la construcción de los significados sociales de cada labor y del chumbe en general. El hecho de portar el chumbe, y de esa manera portar también los contenidos que posee, es una forma de conexión de los ingas con su cultura, con su cosmovisión y con su identidad.

De la misma manera, las técnicas que usan las tejedoras se entrelazan con los significados e interpretaciones que el pueblo inga le ha otorgado al chumbe; por medio de la construcción de las labores es que se recuerda la codificación de la memoria sobre temas del saber inga: el ser humano, la naturaleza, su ubicación espacio-temporal o los elementos de uso cotidiano. En resumen, las características culturales y mentales del chumbe se observan por medio de su elaboración, la red de significaciones que contiene, el entrelazamiento de las interpretaciones en cada una de las labores y la forma en que el pueblo inga sigue manteniendo en él un arte de la memoria que condensa y contiene gran parte de su saber como pueblo. Por tal motivo, cuando indagamos en la forma en que las mujeres ingas tejen el chumbe, decimos que lo hacen con la mente, porque en ella parece que está contenida la trasfiguración de las experiencias sensitivas, generando memoria, símbolos y la red de significaciones que después se hacen materia en cada una de las labores que forman el chumbe inga.

\section{Referencias citadas}

Artesanías de Colombia (junio 2017). Convenio Interadministrativo No 271 de 2015 suscrito entre la Nación - Ministerio de Comercio, Industria y Turismo y Artesanías de Colombia, S.A. Programa de fortalecimiento productivo y empresarial para los pueblos indígenas en Colombia. Comunidad Camëntsá-Inga (San Francisco, Departamento de Putumayo).

Baena, J. (1998). Identidad y trascendencia de simbologías ancestrales. Colombia: Fondo Mixto para la promoción de las artes y la cultura. 
Banks, M. (2001). Visual Methods in Social Research. London: Sage.

Bonilla, V. (1968). Siervos de Dios y amos de indios: el estado y la misión capuchina en el Amazonas. Bogotá: Ed. Stella.

Cereceda, V. (2010) Semiología de los textiles andinos: las talegas de Isluga. Chungara. Revista de Antropología Chilena, 42(1), 181-198.

Cereceda, V. (2011). Verónica Cereceda: el lenguaje de los tejidos andinos. Video subido en YouTube por Arispe, Fernando [AribibiTv] (4 de marzo de 2011). [Archivo de video]. Recuperado de: https://youtu.be/ Bwc1Y3_j7DY

Del Solar, M. (2016). La recreación del Challpi Wathrako en la identidad wanka desde las primeras décadas del S. XX. Producción de fajas tejidas en el valle del Mantaro, Junín, Perú. Nuevo Mundo Mundos Nuevos [online], Workshops, Recuperado de: http://journals.openedition.org/nuevomundo/69890.

Departamento Nacional de Planeación (2005). La visibilización estadística de los grupos étnicos colombianos. DANE, Presidencia de la República de Colombia. Recuperado de: https://www.dane.gov.co/files/censo2005/etnia/sys/visibilidad_estadistica_etnicos.pdf

Duncan, R. (1992). Precolumbian design motifs in inga chumbes. América Negra, 3, s.p.

Gómez, A. (2005). El Valle de Sibundoy: el despojo de una heredad. Los dispositivos ideológicos, disciplinarios y morales de dominación. Anuario Colombiano de Historia Social y de la Cultura, 32, 51-73.

Gómez I. (2012). Las formas de tejer la vida: ¿cómo vivir una experiencia inga a través del diseño, en el museo de trajes regionales? Tesis de pregrado. Universidad Javeriana, Bogotá, Colombia.

Gorman, G. E., y Clayton, P. (2005). Qualitative research for the information professional: A practical handbook (2a ed.). London: Facet Publishing.

Gutiérrez, J. (2007). Los indios de Pasto contra la República (1809-1824). Bogotá: Instituto Colombiano de Antropología e Historia.

Gutiérrez, J. (2011). Los indígenas en la independencia. Revista credencial. s.p. Recuperado de: http://www. revistacredencial.com/credencial/historia/temas/los-indigenas-en-la-independencia.

Isava, L. (2009, julio-diciembre). Breve introducción a los artefactos culturales. Estudios, 17(34) pp. 441454.

Jacanamijoy, B. (2014). El arte de contar y pintar la propia historia. Mundo Amazónico, 5, 211-219.

Jacanamijoy, B. (2017). El chumbe inga. Una forma artística de percepción del mundo. Bogotá: Ankla Editores SAS.

Jacanamijoy, E. y Bastidas, L. (2007). Estudio sobre los simbolismos en las manifestaciones artísticas visuales de la comunidad indígena inga de Santiago, Putumayo. Revista Educación y Pedagogía, XIX(49),173183.

Ministerio de Cultura (Colombia). (2016). Caracterización del pueblo inga. Recuperado de: http://observatorioetnicocecoin.org.co/cecoin/files/Caracterizaci\%C3\%B3n\%20del\%20pueblo\%20Inga.pdf.

Ramírez de Jara, M. (1996). “Territorialidad y Dualidad en una Zona de Frontera del Piedemonte Oriental: El Caso del Valle de Sibundoy”. En Caillavet, C. y Pachón, X. (Eds.). Frontera y poblamiento: estudios de 
historia y antropología de Colombia y Ecuador (pp. 111-136). Quito: Institut Français d'Études Andines. Recuperado de: https://books.openedition.org/ifea/2501?lang=es\#ftn19

Ramírez de Jara, M. C. y Urrea Giraldo F. (1990). Dinámica Etnohistórica Sociodemográfica y Presencia Contemporánea del Curanderismo Ingano- Kamsá en las Ciudades Colombianas. Boletín socio-económico, 20, 123-156.

Restrepo, N. (2006). La Iglesia Católica y el Estado Colombiano, construcción conjunta de una nacionalidad en el sur del país. Tabula Rasa, 5, 151-165.

Rostworowski, M. (1999). Historia del Tahuantinsuyo. Lima: Instituto de Estudios Peruanos.

Salcedo, J. E. (2004). Las vicisitudes de los jesuitas en Colombia durante el siglo XIX. Theologica Xaveriana, $152,679-692$.

Severi, C. (2009). Lunivers des arts de la mémoire. Anthropologie d'un artefact mental. Annales. Histoire, Sciences Sociales (64e année), 463-497.

Tandioy, F. y Maffla, A. (s.f.). Simbolismos de los carnavales inga y kamentsa del Valle de Sibundoy (Alto Putumayo). Hechos y proyecciones del lenguaje, 10, s.p. Recuperado de: http://revistas.udenar.edu.co/index. $\mathrm{php} / \mathrm{rheprol} /$ issue/view/122

Tavera, L. y Johnston, H. (2017). "Artefactos de protesta en el campo del movimiento social mexicano: Reflexiones en torno al "hijastro" del análisis cultural". En Almeida, P. y Cordero Ulate, A. (Eds.). Movimientos Sociales en América Latina: Perspectivas, Tendencias y Casos (pp. 115-142). Buenos Aires: CLACSO.

Urton, G. (1998). From knots to narratives: Reconstructing the art of historical record keeping in the Andes from Spanish transcriptions of Inka khipus. Ethnohistory, 45(3), 409-438.

Williams, R. (2016). Visual tools for visual times - innovation and opportunity in the visual sociology of religión. Ciências da Religião: história e sociedade, São Paulo, 14(2), 98-130. Recuperado de: http://editorarevistas.mackenzie.br/index.php/cr/article/viewFile/10312/6813 